\title{
Duración promedio y algunas estadísticas de los juicios en materia de responsabilidad civil extracontractual en Ciudad de México (1995-2008)
}

\author{
Juan Carlos Marín González*
}

\begin{abstract}
RESUMEN
El tiempo que tardan los tribunales de justicia en resolver las disputas que las partes someten a su decisión, es un elemento que se tiene cada vez más en consideración a la bora de analizar cómo funcionan la economía y la democracia en los países. Algunos organismos internacionales han puesto particular atención en este rubro. Extrañamente en México los estudios acerca de la duración de los procesos judiciales son muy escasos. El presente trabajo pretende ser un aporte en este tipo de mediciones, para ello se ha concentrado en una de las entidades que conforman los Estados Unidos Mexicanos: Ciudad de México. Se han analizado allí la duración de los juicios ordinarios en materia de responsabilidad civil extracontractual entre 1995 y 2008. El resultado es, en cierto sentido, gratificante: estos procesos tienen una duración promedio un poco inferior a los tres años, lo que es significativamente menor de lo que duran en otras latitudes, incluso en países más desarrollados. Pero, por el otro, es muy desalentador porque debido a la especial configuración del denominado amparo directo se produce un juego muy disfuncional entre la justicia local y la federal, que termina por relativizar mucho el dato anterior y muestra que los abogados solo acuden a las instancias locales como una excusa para poder llegar a la justicia federal donde realmente se decide el litigio.
\end{abstract}

$$
\begin{aligned}
& \text { Justicia local y federal - responsabilidad civil extracontractual - } \\
& \text { duración procesos judiciales }
\end{aligned}
$$

* Licenciado en Ciencias Jurídicas y Sociales, Universidad de Chile. Doctor en Derecho, Universidad Carlos III de Madrid, España. Profesor del Tecnológico de Monterrey, México. Correo electrónico: jcmaring@ itesm.mx.

Deseo agradecer a todas aquellas personas que hicieron posible la elaboración de este trabajo, pidiendo, desde luego, una sincera disculpa por algún involuntario olvido. En primer término, a las autoridades del ITAM, especialmente al doctor Jorge Cerdio Herrán, por todo el apoyo brindado para hacerlo realidad. A los profesores de derecho del ITAM que asistieron en marzo de 2015 a la discusión de un primer borrador de este documento. Gracias por sus valiosas observaciones. A Laura Aquino, José Ángel Santiago, Víctor Meyer Suárez y Eduardo Cortés Vázquez, todos exalumnos míos y hoy distinguidos abogados, por el magnífico trabajo que realizaron en la captura de los datos que aquí se muestran y por el aporte que brindaron en las constantes discusiones que ello nos generó. A la maestra Marina Amezcua Milán, por la valiosa información proporcionada respecto del juicio de amparo directo. A los dos árbitros anónimos de esta revista por los lúcidos comentarios efectuados en sus respectivos arbitrajes. Finalmente, a la doctora Josefina Cortés Campos por las valiosas sugerencias de forma y de fondo vertidas en una versión preliminar de este documento.

Artículo recibido el 28.9.2016 y aceptado para su publicación en este número el 5.1.2018. 


\title{
Average duration and related statistics of tort lawsuits in Mexico City
}

\begin{abstract}
The time that courts take to resolve legal disputes for the parties before them, at the trial level, is an important indicator that should be taken into account when evaluating the economy and the prospects for democracy in a country. Several international organizations have paid close attention to the duration of trials. Unfortunately, in Mexico studies that look into the duration of trials are scarce and far too few. This paper hopes to contribute to the information available on this topic, with respect to one of the jurisdictions that make up Mexico, the federal district that comprises Mexico City. Specifically, we take a look at the duration of tort trials there between 1995 and 2008. The data we uncover is surprising in quite a positive way, tort trials in Mexico City take on average about three years to be argued and decided, which is less time that in many other latitudes, even in developed countries. Yet, in another sense, we strike a cautionary tone in interpreting the data. Many such trails continue in Mexico from the local to the federal level, through the abuse of amparo remedies.
\end{abstract}

Local and federal justice - torts - duration tort trial

\section{INTRODUCCIÓN}

$\mathrm{E}$ n México son escasos los estudios que buscan medir el tiempo que tardan los procesos judiciales en resolverse. Esta situación se predica tanto en el plano nacional (Poder Judicial Federal) como en el de cada una de las diversas entidades federativas que conforman los Estados Unidos Mexicanos (Poderes Judiciales Locales). Esta situación es deseable que se corrija. Las instituciones públicas y privadas debieran destinar recursos materiales y humanos a este rubro. En un mundo globalizado estas mediciones son importantes ${ }^{1}$. No se olvide que el funcionamiento de los sistemas judiciales es uno de los elementos que los organismos internacionales tienen en cuenta a la hora de establecer el nivel de desarrollo económico de los países ${ }^{2}$. Lo anterior ha

${ }^{1}$ En general véase: A. Uzelac (ed.), Goals of civil justice and civil procedure in cotemporary juidicial system, Springer, 2014; Ch. van Rhee and F. Yulin, Editors, Civil litigation in China and Europe, Springer, $2014 ; \mathrm{L}$. Ervo and A. Nylund (eds.), The future of civil litigation. Access to courts and courts-annexed mediation in Nordic countries, Springer, 2014; X.E. Kramer and Ch. van Rhee (eds.), Civil litigation in a globali-zing world, Springer, 2012. J. Maxeiner, Failures of American civil justice in international perspective, Cambridge, 2011; O. Chase y H. Hersjkoff (ed.), Civil litigation in comparative context, Thomson-West, EE.UU., 2007; Van Rhee (ed.), The Law's delay. Essays on undue delay in civil litigation, Intersentia, 2004. N. Trocker and V. Varano (eds.), The reforms of civil procedure in comparative perspective, Torino, 2005. A.A. S., Zuckerman, Civil justice in crisis, Oxford University Press, 2000.

${ }^{2}$ La OCDE, por ejemplo, ha señalado: “Judicial systems serve important purposes in up-holding social values but also in determining economic performance. Well-functioning judiciaries guarantee security of property rights and enforcement of contracts. Security of property rights strengthens incentives to save and invest, by protecting returns from these activities. A good enforcement of contracts stimulates agents to enter 
llevado a los operadores jurídicos de algunas naciones a buscar fórmulas que intenten hacer realidad lo que diversas constituciones consagran como el derecho a un proceso "sin dilaciones indebidas"3.

México podría tomar como referente lo que, por ejemplo, se viene haciendo desde hace quince años en Europa. Allí, el año 2002 se creó mediante Resolución Res(2002)12, del Comité de Ministros del Consejo de Europa, la Comisión Europea para la Eficacia de la Justicia (CEPEJ), con un doble propósito: “(a) mejorar la eficacia y el funcionamiento del sistema de justicia de los Estados miembros, con el objeto de asegurar que toda persona dentro de su jurisdicción puedan hacer valer sus derechos eficazmente, generando, de esta forma, mayor confianza en el sistema de justicia entre los ciudadanos; y (b) permitir una mejor puesta en práctica de los instrumentos jurídicos internacionales del Consejo de Europa referente a la eficacia e imparcialidad de la justicia" ${ }^{4}$.

La referida Comisión ha trabajado desde entonces en la medición del tiempo que alcanzan los procesos judiciales en los diversos países de Europa, tratando de homogeneizar

into economic relationships, by dissuading opportunistic behaviour and reducing transaction costs. This has a positive impact on growth through various channels: it promotes competition, fosters specialisation in more innovative industries, contributes to the development of financial and credit markets and facilitates firm growth”. OECD (2013), "What makes civil justice effective?", OECD Economics Department Policy Notes, No. 18 June 2013, p. 2. Ver, asimismo, The World Justice Project. Rule of Law Index, 2015. The World Justice Project es una organización independiente que promueve el desarrollo del estado de derecho en el mundo. El índice describe cómo funciona en la práctica el estado de derecho de acuerdo con un conjunto de datos (47 indicadores) agrupados en nueve temas. Uno de ellos, el número siete, se refiere a la justicia civil: "Factor 7 Civil Justice. measures whether ordinary people can resolve their grievances peacefully and effectively through the civil justice system. The delivery of effective civil justice requires that the system be accessible and affordable (7.1), free of discrimination (7.2), free of corruption (7.3), and without improper influence by public officials (7.4). The delivery of effective civil justice also necessitates that court proceedings are conducted in a timely manner and not subject to unreasonable delays (7.5). Finally, recognizing the value of Alternative Dispute Resolution mechanisms (ADRs), this factor also measures the accessibility, impartiality, and efficiency of mediation and arbitration systems that enable parties to resolve civil disputes (7.7)", p. 13 (La justicia civil para ser efectiva requiere cumplir con las siguientes características: ser accesible para los ciudadanos y razonable en términos económicos; que no exista discriminación ni corrupción en su interior; que no haya una injerencia indebida de otros funcionarios públicos; que el proceso culmine en un plazo razonable; que las sentencias puedan ejecutarse; y, finalmente, que el sistema cuente con métodos alternativos de solución de controversias $(A D R)$ que sean accesibles, imparciales y eficientes). México en el rubro justicia civil ocupa el lugar 82 de 102 países y el 13 de 19 países en Latinoamérica, p. 115.

${ }^{3}$ En la declaración de derechos de Maryland el 3 de noviembre de 1776 se señaló: "That every freeman, for any injury done to him in his person, or property, ought to have remedy by the course of the law of the land, and ought to have justice and right, freely without sale, fully without any denial, and speedily without delay, according to the law of the land" (Énfasis añadido). Por su parte, el Tratado de Niza del año 2000 establece en su art. 47 inc. $2^{\circ}$ lo siguiente: "Toda persona tiene derecho a que su causa sea oída equitativa y públicamente y dentro de un plazo razonable por un juez independiente e imparcial, establecido previamente por la ley. Toda persona podrá hacerse aconsejar, defender y representar" (Énfasis añadido).

${ }^{4}$ Artículo 1 Estatuto de la CEPEJ. Apéndice 1 de la Resolucioón Res(2002)12: "(a) to improve the efficiency and the functioning of the justice system of member states, with a view to ensuring that everyone within their jurisdiction can enforce their legal rights effectively, thereby genera-ting increased confidence of the citizens in the justice system and (b) to enable a better implementation of the international legal instruments of the Council of Europe concerning efficiency and fairness of justice". 
la información estadística que estos generan. De este modo la Comisión ha producido unas directrices (GOJUST Guidelines) que son útiles a la hora de comparar lo que sucede en cada país y, de esta forma, establecer qué mejoras se pueden implementar en cada uno de sus sistemas judiciales. Uno de los indicadores que utiliza la CEPEJ, entre otros, es el denominado Clarence Rate (CR), que permite comparar cada año la carga de trabajo que mantienen los tribunales en cada país. El indicador analiza el número de procesos judiciales que ingresan cada año a los respectivos sistemas judiciales, en relación con el número de procesos que son resueltos (los que salen del sistema) ${ }^{5}$. Lo anterior ha permitido confeccionar un cuadro más preciso de lo que sucede en materia judicial en cada Estado europeo y, de este modo, determinar cuáles muestran un buen desempeño y cuáles no ${ }^{6}$.

Mientras en México las autoridades y los distintos operadores jurídicos toman conciencia de lo anterior, el presente trabajo busca ser una pequeña contribución en este tema. En él se analiza la duración promedio de los procesos declarativos en materia de responsabilidad civil extracontractual en Ciudad de México (Distrito Federal), en sus dos instancias más el juicio de amparo en el período 1995-2008 ${ }^{7}$. Adicionalmente se estudian varios datos estadísticos respecto de este tipo de procesos judiciales. He dicho procesos declarativos porque en este documento no se examina la eventual fase de ejecución. Como es bien sabido, si la sentencia de segunda instancia acoge -toda o alguna- de las pretensiones indemnizatorias formuladas por el actor en su demanda, este debe iniciar el respectivo proceso de apremio a menos que el demandado decidiera, por alguna extraña razón, cumplir voluntariamente con el fallo ${ }^{8}$.

5 "El índice Clearence, expresado como un porcentaje, se obtiene dividiendo el número de procesos resueltos por el número de procesos entrantes y multiplicando el resultado por 100". En el referido informe se expresa que "A Clearance Rate close to $100 \%$ indicates the ability of the court or of a judicial system to resolve more or less as many cases as the number of incoming cases within the given time period. A Clearance Rate above $100 \%$ indicates the ability of the system to resolve more cases than received, thus reducing any potential backlog. Finally, if the number of incoming cases is higher than the number of resolved cases, the Clearance Rate will fall below $100 \%$. When a Clearance Rate goes below $100 \%$, the number of unresolved cases at the end of a reporting period (backlog) will rise. Essentially, a Clearance Rate shows how the court or judicial system is coping with the in-flow of cases". CEPEJ Report on "European judicial systems - Edition 2014 (2012 data): efficiency and quality of justice", p. 191.

${ }^{6}$ Al momento de enviar este trabajo para su publicación se anunció que el informe del año 2016 se haría público el 6 de octubre de 2016 en Paris. Ver http://www.coe.int/t/dghl/cooperation/cepej/evaluation/ default_en.asp

${ }^{7}$ Con la finalidad de no alargar más la elaboración de este escrito se decidió detener el análisis de los datos el año 2008. En un segundo trabajo examinaré las estadísticas de los años 2009 a la fecha.

${ }^{8}$ En el sistema jurídico mexicano, al igual que sucede por ejemplo en el chileno, la sentencia que se puede ejecutar es la de segunda instancia, aun cuando no esté firme (artículo 694 párrafo tercero del Código de Procedimientos Civiles del Distro Federal, en adelante CPCDF). El denominado juicio de amparo, que en este punto funciona de manera muy similar al recurso de casación, no suspende, por regla general, la ejecución de la sentencia del tribunal ad quem. 
En este texto se investiga tanto la duración promedio de cada instancia como la del proceso judicial en su conjunto9 ${ }^{9}$. Esta última medición es, en todo caso, difícil de lograr. Hay demasiadas variables que no controlamos. Por ello los datos de este ensayo -en relación con la duración del proceso judicial en su conjunto- son solo indicativos. Me explico: en cada uno de los procesos analizados he tomado como último dato de la investigación la fecha en la que se resolvió el amparo directo independientemente de si este acogió o rechazó la petición del recurrente (quejoso) y, por tanto, sin saber si el proceso continuó o no ante los jueces locales. La medición, por tanto, solo se puede considerar precisa cuando se rechaza el amparo. En cambio, ella no es exacta en aquellos casos en los que el proceso continúa, esto es, cuando el amparo se acoge ${ }^{10}$. Volveré sobre este aspecto un poco más adelante.

Antes de abordar la metodología empleada deseo aclarar, brevemente, algunos puntos adicionales para una mejor comprensión del trabajo. El primero dice relación con el derecho civil en México; el segundo con el proceso judicial mismo en sus diversas fases: primera y segunda instancia (nivel local) y el juicio de amparo directo (nivel federal); y el tercero con la creación y publicación de las tesis en el Semanario Judicial de la Federación (SJF).

\section{DeRECHO CIVIL Y PROCESO JUDICIAL}

\section{Derecho civil}

El derecho civil en México es, de acuerdo con la distribución de competencias previstas en la Constitución Política, un asunto local, es decir, atribución de cada uno de los estados que integran la República mexicana. Lo anterior significa dos cosas: (i) en materia legislativa, que la facultad para crear y modificar este derecho es propia de cada congreso local. En el caso de Ciudad de México esta competencia recae en la Asamblea Legislativa, según lo dispone el artículo 122, C, Base primera, V, h, de la Constitución Política. En el país, por tanto, coexisten treinta y dos sistemas civiles diversos, los que normativamente hablando no tienen mayor conexión salvo la de respetar el Texto Constitucional Federal (artículo 133). Este trabajo se refiere a solo uno de estos

\footnotetext{
${ }^{9}$ Para efectos de este trabajo entendemos por "proceso judicial en su conjunto" aquel que incluye una primera y una segunda instancia ante los jueces locales y un amparo directo (amparo de casación) ante los jueces federales. Lo importante para nosotros no es la cuestión técnica de cada una de estas fases, sino la posibilidad real que tienen las partes involucradas en la disputa de ganarla o perderla. En México las partes pueden ganar o perder el pleito en cualquiera de estas tres fases. Luego veremos, en todo caso, que debido a la particular configuración del amparo directo es posible que se dicte más de una sentencia de segunda instancia y que se presente más de un amparo en su contra. Acerca de esta situación no tenemos mayor control porque no hay un sistema estadístico que permita rastrear estas sucesivas sentencias y amparos.

${ }^{10}$ Hacer el seguimiento de la continuación del proceso judicial del plano local al federal es prácticamente imposible, al no tener un sistema estadístico que relacione el número que se asigna al amparo directo, en el tribunal federal, con el número asignado a la apelación (llamada toca) en el tribunal local.
} 
sistemas: el que rige en Ciudad de México (Distrito Federal); (ii) en materia judicial, que la competencia para resolver los litigios civiles es, en principio, de los tribunales de primera y de segunda instancias que integran los respectivos poderes judiciales locales (estatales). En el caso de Ciudad de México de los jueces y magistrados que conforman el Tribunal Superior de Justicia del DF (TSJDF). Y decimos en principio porque estos poderes judiciales locales, a diferencia de sus homólogos en EE.UU., no son órganos límites. No tienen en su vértice una Corte Suprema local, lo que permite a las partes saltar de este plano al federal para revocar la sentencia de segunda instancia emitida por el órgano estatal, según lo explicaremos un poco más adelante.

\section{Proceso judicial ante el Tribunal Superior de Justicia del Distrito Federal (TSJDF)}

Una demanda de daños y perjuicios por un ilícito extracontractual superior a US\$25.500 (veinticinco mil quinientos dólares de Estados Unidos de Norteamérica) ${ }^{11}$ se tramita en Ciudad de México en doble instancia (artículo 691 inciso tercero CPCDF). La primera se desarrolla ante un único juez (juzgado de lo civil, artículo 50 fracción III, Ley Orgánica del Tribunal Superior de Justicia del Distrito Federal, en adelante LOTSJDF), denominado juez a quo. La segunda ante tres magistrados que integran una sala del referido tribunal (sala de lo civil artículo 43 fracción I, LOTSJDF), denominado ad quem.

Las dos instancias tienen plena competencia para resolver el fondo de la disputa. Evidentemente la jerarquía de ambos tribunales es diversa. Esto quiere decir que la sentencia de segunda instancia cuando revoca o confirma la de primera es, aunque suene obvio, una sentencia de segunda instancia y no una nueva de primera. De inmediato veremos que en el sistema jurídico mexicano la sentencia "verdaderamente" importante es la del tribunal ad quem.

Ahora bien, sin perjuicio de la importancia que le hemos atribuido a esta última sentencia ella no se publica. En el sistema jurídico mexicano las sentencias de instancia no son de público conocimiento ${ }^{12}$. Por esta razón es muy difícil acceder a las mismas, lo que obliga a trabajar directamente con los amparos donde una parte de su contenido suele reproducirse.

\section{Proceso judicial ante los Tribunales Colegiados de Circuito (TCC)}

Con la sentencia del tribunal ad quem -sea que hubiere confirmado la del juez a quo, sea que la hubiere revocado- termina el proceso en el ámbito local. La parte agraviada con la sentencia de segunda instancia (el actor, el demandado o ambos) puede saltar, como hemos avanzado, de la esfera local a la federal promoviendo el respectivo amparo

11 Al tipo de cambio del 19 de septiembre de 2016.

${ }^{12}$ Excepcionalmente el TSJDF publica un número muy menor de estas sentencias en su revista denominada Anales de Jurisprudencia. Ver http://www.poderjudicialdf.gob.mx/en/PJDF/Revista_de_Anales_de_Jurisprudencia 
directo $^{13}$. Los órganos competentes para conocer de este recurso son los Tribunales Colegiados de Circuito (TCC). En el caso de Ciudad de México los del Primer Circuito en materia civil (artículo 37, fracción I, letra c) Ley Orgánica del Poder Judicial Federal). Es de resaltar que este amparo funciona de manera muy similar a la forma como lo hace el recurso de casación en Francia y en los países del Cono Sur Americano ${ }^{14}$.

En términos muy generales, si el TCC rechaza el amparo el proceso declarativo termina. La sentencia del tribunal ad quem queda firme, sea que hubiere rechazado la demanda indemnizatoria, sea que la hubiere acogido. Evidentemente en el primer evento no hay nada más que hacer. En el segundo, en cambio, se dará lugar a la fase de ejecución de la sentencia, si es que esta no se hubiere ya iniciado. No olvidemos que, normalmente, el amparo directo no suspende dicha ejecución (artículo 190 Ley de Amparo). En cambio, si la sentencia del TCC acoge el amparo se debe reenviar el asunto para que el tribunal ad quem dicte una nueva sentencia de segunda instancia, de acuerdo con los lineamientos que ha dado el tribunal federal al momento de fallar el amparo ${ }^{15}$. En el sistema jurídico mexicano los TCC no tienen competencia para resolver directamente el fondo de la disputa. Por esta razón en párrafos anteriores señalé que la sentencia "verdaderamente" importante era la de segunda instancia. Es esta la que siempre resuelve la disputa, sea que refleje la opinión de los jueces locales, sea que refleje la opinión de los federales.

${ }^{13}$ Esto es disfuncional. Obliga la intervención de tribunales federales para resolver un problema local, aplicando la legislación civil local. La justificación parece residir en la escasa confianza histórica que se tiene de los tribunales locales. En el sistema judicial de EE.UU., en cambio, la esfera local es completa. Termina con una Suprema Corte Estatal. Los procesos civiles que comienzan en el ámbito local terminan en él. Los que, en cambio, inician en el federal terminan en el federal. No existe la posibilidad de saltar de una esfera a la otra. Para la situación mexicana véase Héctor Fix-Zamudio y José Ramón Cossío, El poder judicial en el ordenamiento mexicano, México, Fondo de Cultura Económica, 1996 (reimpresión 1999). Para el sistema de EE.UU., vid. Joseph W. Glannon, Civil Procedure, New York, Wolters Kluwer, 2013. Erwin Chemerinsky, Federal jurisdiction, New York, Wolters Kluwer, 5a. ed., 2007.

${ }^{14}$ Señala al respecto Héctor Fix-Zamudio: "Si ahora intentamos una visión panorámica y de conjunto del procedimiento en el amparo directo o de única instancia, podremos observar que, sin pretenderlo intencionalmente, se encuentra orientado, por las necesidades ineludibles de la práctica, hacia la tramitación de un simple recurso, que, por otra parte, sigue muy de cerca los lineamientos del recurso de casación". "Reflexiones sobre la naturaleza procesal del amparo", en Ensayos sobre el derecho de amparo, México, Porrúa, $2^{\text {a }}$. ed., 1999, p. 130. En el mismo libro véase "Presente y futuro de la casación civil a través del juicio de amparo mexicano", pp. 237-284. Para el derecho francés véase: Jacques Boré, y Louis Boré, La Cassation en matière civile, Paris, Dalloz, 2008. Maylis Douence y Marc Azavant, Institutions Jurisdictionnelles, Paris, Dalloz, $2^{\text {a }}$. ed., 2014.

${ }^{15}$ Esto es extraño. En los sistemas procesales que admiten el recurso de casación con reenvío lo normal es que el tribunal al que se remite el asunto sea diverso del que ya lo resolvió. Este último, lógicamente, se encuentra inhabilitado al haber emitido opinión respecto del fondo de la disputa. Por eso el art. 170 del CPCDF, dentro de los impedimentos y excusas que tienen los jueces para conocer de un asunto señala: "Todo magistrado, juez o secretario se tendrá por forzosamente impedido para conocer en los casos siguientes: [...] $\mathrm{X}$. Si ha conocido del negocio como juez, árbitro o asesor, resolviendo algún punto que afecte a la sustancia de la cuestión, en la misma instancia o en otra". 


\section{TESIS: CREACIÓN Y PUBLICACIÓN EN EL SEMANARIO JUDICIAL DE LA FEDERACIÓN (SJF)}

El TCC puede -si así lo deciden sus magistrados- confeccionar una o más tesis respecto del asunto que han debido resolver conociendo del amparo directo ${ }^{16}$. Lo anterior con independencia de si este se acogió o no. Esta es una decisión potestativa de los magistrados. Si los referidos jueces no confeccionan la tesis es muy difícil para los terceros ajenos a la disputa (digamos los profesores que nos interesamos por las decisiones de los tribunales) llegar a conocer el respectivo proceso. Se comprenderá, entonces, que si los magistrados no desean que sus resoluciones sean analizadas y, eventualmente, comentados por la academia, tienen un notable incentivo para no hacer tesis. En términos prácticos solo las partes del litigio van a conocer lo resuelto. Lo anterior es contraproducente para una democracia y debería, por tanto, corregirse. Los TCC deberían subir a Internet sus sentencias tan pronto estén firmadas con independencia de si deciden confeccionar una tesis o no ${ }^{17}$.

Por el contrario, si los magistrados deciden redactar una o más tesis entonces sí podemos conocer el amparo que le o les sirve de antecedente. Una vez redactada la tesis se envía para su publicación en el SJF (artículos 219 y 220 de la Ley de Amparo). Una vez publicada (normalmente unos tres o cuatro meses después que el asunto se resolvió) se puede conocer el número del amparo y pedirlo por medio de la Ley Federal de Transparencia y Acceso a la Información Pública ${ }^{18}$. Esto es lo que hemos hecho en este trabajo. Ya veremos que esto equivale a ver una película exactamente al revés.

Veamos alguna información de lo que hemos señalado y criticado. Analicemos en el período 1995-2008 cuántos procesos conocieron los Tribunales Colegiados del Primer Circuito en materia de responsabilidad civil extracontractual, partiendo de la tesis publicada hacia atrás.

${ }^{16}$ La tesis no es conocida en el derecho comparado. Es una norma general que busca sintetizar en unas pocas líneas, sin referencia a los hechos del pleito, el tema principal que los magistrados debieron enfrentar. Es una regla jurídica a mitad de caballo entre la ley, norma general y abstracta, y la sentencia que resuelve el caso concreto, donde se asientan los hechos de la causa. Su utilidad es muy discutible. No me opongo, en todo caso, a su existencia. Me opongo a que solo se publique la tesis y no el amparo que la originó. Para confeccionar la tesis la única exigencia legal es que haya un "criterio relevante" en el parecer de los magistrados. Vid. artículo 218 de la Ley de Amparo.

${ }^{17}$ El resto es trabajo de las empresas que están acostumbradas a trabajar con bases de datos judiciales: Dalloz, West Law, Lexis Nexis, Tirant Lo Blanch, etc. Existe una página del Consejo de la Judicatura Federal en la que con el número del expediente se pueden ver las sentencias emitidas por los tribunales del Poder Judicial de la Federación. La página no es fácil de consultar y, en todo caso, la idea es poder hacerlo sin el número del expediente. Que simplemente el amparo esté disponible: http://www.dgepj.cjf.gob.mx/paginas/ serviciosTramites.htm? pageName =servicios $\% 2$ Fexpedientes.htm

${ }^{18}$ Diario Oficial de la Federación del 9 de mayo de 2016, que abrogó la anterior ley sobre la materia de 11 de junio de 2002. En el mejor de los casos, por tanto, en México tenemos un retraso en el conocimiento de los amparos de los TCC de unos tres o cuatros meses desde que fueron resueltos. 


\begin{tabular}{|l|c|}
\hline Tribunal & Tesis \\
\hline Primer Tribunal Colegiado & 1 \\
\hline Segundo Tribunal Colegiado & 1 \\
\hline Tercer Tribunal Colegiado & 17 \\
\hline Cuarto Tribunal Colegiado & 2 \\
\hline Quinto Tribunal Colegiado & 2 \\
\hline Sexto Tribunal Colegiado & 8 \\
\hline Séptimo Tribunal Colegiado & 8 \\
\hline Octavo Tribunal Colegiado & 8 \\
\hline Noveno Tribunal Colegiado & 2 \\
\hline Décimo Tribunal Colegiado & 1 \\
\hline Undécimo Tribunal Colegiado & 10 \\
\hline Duodécimo Tribunal Colegiado & 0 \\
\hline Decimotercer Tribunal Colegiado & 1 \\
\hline Decimocuarto Tribunal Colegiado & 0 \\
\hline Total tesis: & 61 \\
\hline
\end{tabular}

Tesis de los Tribunales Colegiados en materia civil del Primer Circuito

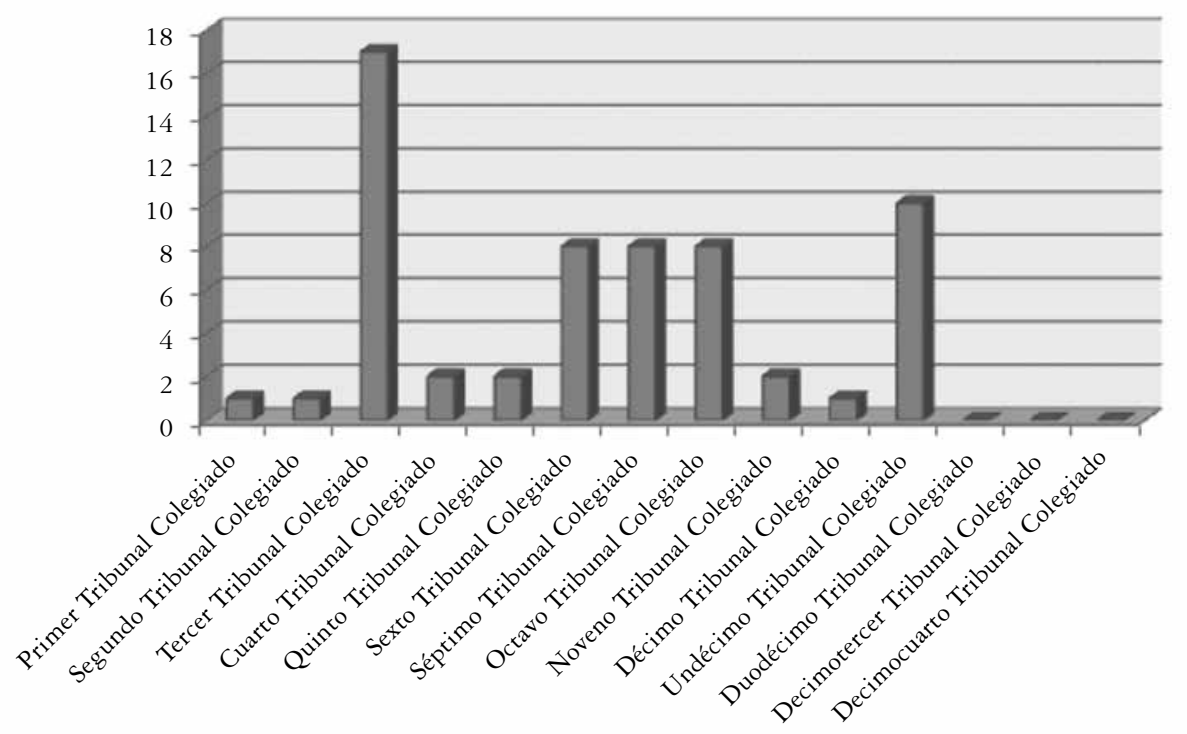

El lector atento ya se habrá percatado de que hay tribunales colegiados muy proclives a confeccionar tesis y otros, por el contrario, muy reacios. Se podría argumentar que en el período 1995-2008 los tribunales Duodécimo y Decimocuarto no conocieron de ningún amparo relativo a la materia analizada y por ello no confeccionaron ninguna 
tesis $^{19}$. Pero esto sería extraño si tenemos en mente que en el mismo período el Tercero o el Undécimo, por ejemplo, conocieron de varios amparos. Si el sistema de adjudicación de causas al interior de los Tribunales Colegiados del Primer Circuito está bien confeccionado el argumento anterior es insostenible. La única explicación factible es que los dos tribunales mencionados conocieron de algunos amparos en materia de responsabilidad civil extracontractual, pero no confeccionaron ninguna tesis porque en su parecer no hubo criterio relevante alguno en el amparo en cuestión.

La misma gráfica anterior ahora expresada en términos porcentuales nos muestra lo siguiente:

\section{Actividades de los TCC}

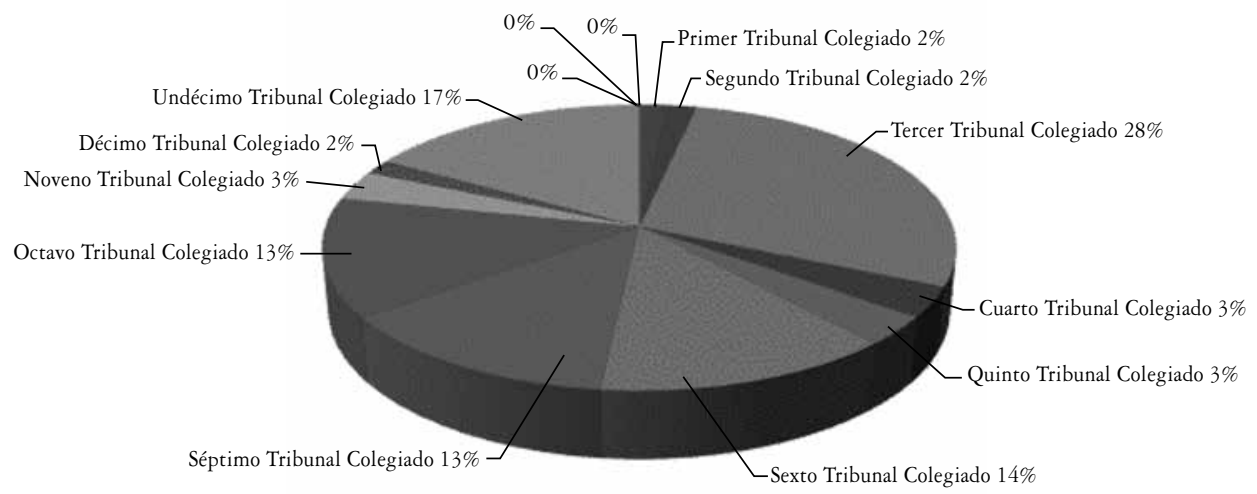

Es notable cómo cinco TCC $\left(3^{\circ}, 6^{\circ}, 7^{\circ}, 8^{\circ}\right.$ y $\left.11^{\circ}\right)$ concentran el $85 \%$ de los amparos en esta materia.

\section{Metodología}

Ya he avanzado que la metodología empleada es algo así como ver una película al revés. Empezamos por las tesis que se publican tres o cuatro meses después de resuelto el respectivo amparo. Lo primero que se hizo, por tanto, fue analizar el SJF entre 1995

${ }^{19}$ Del Decimotercer Tribunal Colegiado -que también figura con cero amparos- tenemos dos sobre la materia. Uno debió incluirse en esta estadística; el otro no. El primero es el AD 71/2002 de 11 de junio de 2002, que originó la tesis número de registro 185.414, sobre daño moral de las sociedades mercantiles, publicada en el SJF en diciembre de 2002 (aquí el retraso en conocer la ejecutoria fue de seis meses). El segundo es el AD 630/2002 de 29 de octubre de 2002, que originó la tesis número de registro 185.064, sobre responsabilidad civil objetiva extracontractual derivados de una carta de porte, publicada en el SJF en enero de 2003 (aquí el retraso es de solo tres meses). Este último amparo fue desechado porque la materia, en parecer del referido Colegiado, era contractual. 
y 2008. Se seleccionaron todas las tesis allí publicadas relacionadas con responsabilidad civil. Lo anterior entregó un universo aproximado de cien tesis. Posteriormente -previa refinación de este primer universo- se solicitaron los respectivos amparos que habían originado dichas tesis. Una vez que estos llegaron se inició el proceso de lectura y depuración. Los criterios de exclusión y los problemas encontrados al leer (o tratar de leer) los referidos amparos fueron, en resumen, los siguientes: algunos amparos fueron desechados porque las fechas habían sido borradas o tachadas y eso hacía imposible obtener alguna información útil. Otros fueron descartados porque el amparo mismo no decía relación estricta con los temas que en este ensayo tratamos (por ejemplo, eran de responsabilidad contractual, daños en materia criminal o algún incidente de ejecución de sentencia, pero no un proceso declarativo). Otros amparos simplemente eran ilegibles. Luego de esto, quedó un universo de unos cincuenta amparos que es la materia prima con la que se trabajó.

De cada uno de ellos se intentó extraer la siguiente información ${ }^{20}$ : sentencia de amparo; fecha del evento o accidente; hechos del mismo; fecha de la demanda; nombre del actor; nombre del demandado; pretensiones hechas valer; juzgado y número de expediente en primera instancia; fecha de la sentencia de primera instancia; contenido de la sentencia de $1^{\mathrm{a}}$ instancia (acoge o rechaza la pretensión del actor); fecha de apelación; parte que apela (actor o demandado); Sala del Tribunal Superior de Justicia del DF; número de apelación (toca); fecha de la sentencia de $2^{\mathrm{a}}$ instancia; sentencia de $2^{\mathrm{a}}$ instancia (confirma o modifica); fecha del amparo; quién interpone el amparo (quejoso); Tribunal Colegiado de Circuito; fecha de la sentencia de amparo; contenido de esta sentencia (acoge o rechaza el amparo). Todos estos elementos nos entregaron la información necesaria para medir la duración de los procesos declarativos y obtener algunos datos adicionales que se mostrarán aquí.

\section{DURACión PROMEDIO DEL PROCESO}

La primera instancia es -con alguna distancia- la que más dura en materia de procesos declarativos de responsabilidad civil extracontractual en Ciudad de México. En promedio en los juicios analizados tuvieron una duración de 19,28 meses, esto es, poco menos de dos años. Algunas circunstancias pueden explicar esta situación. En primer término, es el único lugar donde verdaderamente se desahoga la prueba ofrecida por las partes. Esta labor suele consumir mucho tiempo a estas y al tribunal. En esta instancia suelen, también, producirse algunos tiempos muertos que son de exclusiva responsabilidad de los abogados, quienes siguen teniendo en sus manos buena parte del impulso que requiere el proceso para avanzar.

${ }^{20}$ Digo se intentó porque no siempre fue posible llevar a cabo dicha labor. Hubo ocasiones en que los nombres de las partes, la fecha del evento, la fecha de la demanda, la de la contestación, el nombre del juez o de la sala, el número de toca, por citar los ejemplos más recurrentes, era ilegibles. 
La segunda instancia es la que menos dura en el sistema que estamos analizando. En promedio dura 4 meses. Una cifra muy rápida comparada con cualquier otro estudio que se hubiere hecho -dentro y fuera de México- acerca de la duración de los procesos judiciales. Algunos hechos pueden explicar, en parte, la significativa diferencia entre el tiempo que se emplea ante el juez a quo y el que se utiliza frente al ad quem. En general en la segunda instancia la actividad de las partes se limita a presentar el escrito de apelación y a esperar la resolución del mismo (art. 693 CPCDF). No hay actividad que las partes deban o puedan efectuar y, por tanto, no hay posibilidad de tiempos muertos atribuibles a ellas. Tampoco, por regla general, se desarrolla actividad probatoria alguna y no existen alegatos orales. El recurso se resuelve con el solo escrito del apelante.

Finalmente, la duración del proceso ante los TCC es muy breve también, siendo el promedio levemente superior al de la apelación: 4,14 meses. Similar explicación podemos dar en el ámbito federal. La labor de los abogados se concentra en la denominada demanda de amparo. Todo el resto es competencia del respectivo tribunal.

En promedio, por tanto, un proceso declarativo en materia de responsabilidad civil extracontractual ante el TSJDF tiene una duración de 29,23 meses, esto es, casi dos años y medio. Este tiempo es considerablemente menor que la duración que tienen este tipo de procesos judiciales en otros países ${ }^{21}$. Lo anterior, en general, debe ser considerado una buena noticia. Es positivo que las sentencias se pronuncien en un lapso no muy lejano en relación con la presentación de la demanda. El sentido de la justicia se valora más en estos casos. Lo contrario sucede cuando los procesos tardan cinco, diez o más años en resolverse.

Duración juicios responsabilidad civil

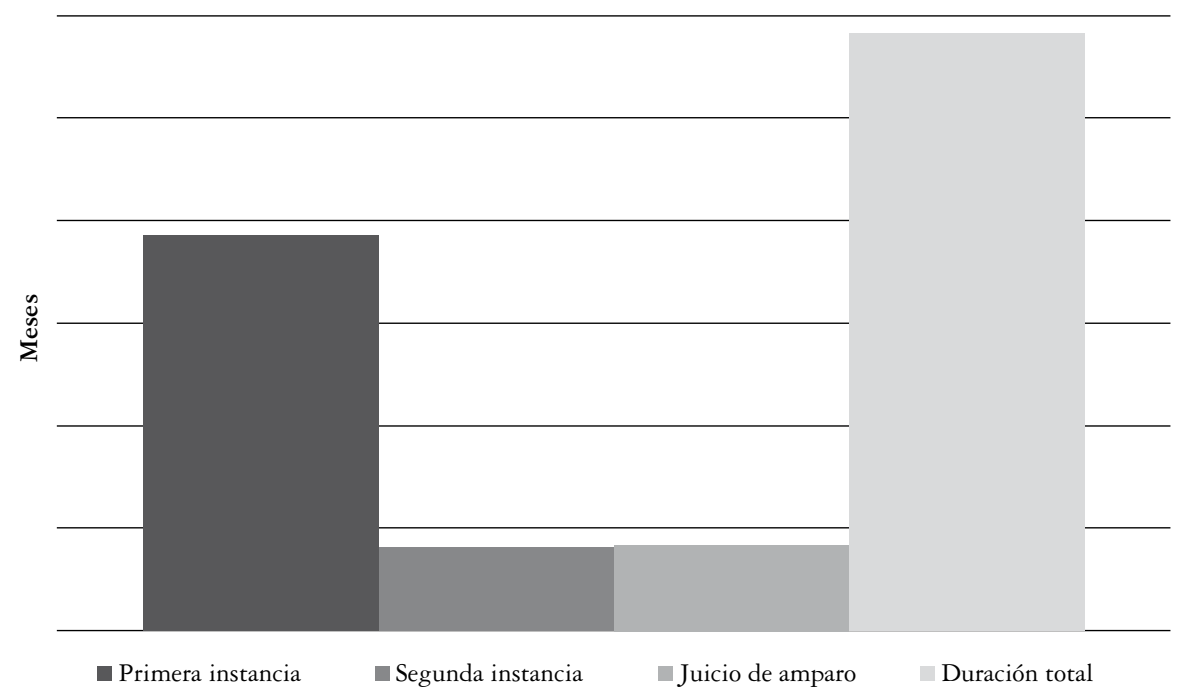

${ }^{21}$ Compárese, por ejemplo, con las cifras que se señalan en los estudios citados en la nota al pie $\mathrm{N}^{\circ} 1$ de este trabajo. 
No se olvide, en todo caso, la advertencia que hicimos al inicio de este trabajo. Solo la duración promedio de cada instancia es precisa. La de todo el proceso judicial solo es indicativa. Pongo un ejemplo de uno de los procesos analizados en este ensayo. En el amparo directo 10283/98 sobre daños a la integridad física por colisión de vehículos a motor, la demanda - presentada el 21 de febrero de 1997- fue rechazada íntegramente tanto en primera como en segunda instancia porque "la actora no probó su acción" 22 . Pues bien, recurrida esta última resolución el Tercer Tribunal Colegiado en materia civil del Primer Circuito concedió el amparo a los actores (los quejosos). Esta ejecutoria se pronunció el 21 de enero de 2000. Este proceso "duró” en su conjunto casi tres años (de febrero de 1997 a enero de 2000), es decir, unos meses más que el promedio que duran estos juicios de acuerdo con nuestra investigación. Ahora bien, es indiscutible que el actor al ganar el amparo va a ganar también el juicio. Pero esto no significa que el proceso haya concluido. Ya sabemos que el Colegiado no tiene competencia para resolver el fondo de la disputa y debe, por tanto, reenviar el expediente al tribunal ad quem para que este dicte una nueva sentencia de segunda instancia, esta vez, acogiendo una o más de las pretensiones de los actores. Todo el tiempo adicional que significa esta nueva sentencia -con otro eventual amparo-y su posterior ejecución no se refleja en este trabajo.

\section{PRIMERA INSTANCIA}

La buena noticia en cuanto a la duración de los juicios que recién hemos visto se ve algo empañada si analizamos lo que sucede en cada instancia y lo que ocurre con las tasas de confirmación o revocación de las sentencias. Si bien el presente estudio no analiza los

22 En breve los hechos fueron los siguientes. Según el relato de los actores el 21 de diciembre de 1996 un camión del demandado invadió ambos carriles de la carretera de Córdoba a Veracruz, ocasionado que la camioneta propiedad de los actores se impactara con un camión de los demandados. En su demanda los actores pidieron: A) El pago de daño moral, daños y perjuicios por los siguientes conceptos: a) El pago de \$100,000.000 por el precio de la camioneta que fue pérdida total por la imprudencia de la camión perteneciente a la empresa, b) El pago de la cantidad de $\$ 1,500,000.00$ por daño moral indirecto por la pérdida de un contrato no cumplido por culpa de los aquí demandados, con perjuicio en el patrimonio de los actores, así como el pago de \$450,000.00 que deben pagarse como cláusula penal, c) El pago por daño moral indirecto de la cantidad de $\$ 360,000.00$ por sueldos y percepciones legales que dejaron de percibir los actores, a razón de \$30,000.00 mensuales cada uno y que durante seis meses dejaran de percibir por la incapacidad y convalecencia médica resultante del accidente en cuestión, puesto que no podrán trabajar por esos meses; d) El pago de \$400,000.00 por el daño moral ocasionado a los actores de este juicio, y a sus hijos menores, quienes debido al accidente, sufren de dolencias y secuelas psicológicas y conductales que afectan su conducta, desarrollo económico, laboral y escolar; B) El pago en dinero de las 2/3 partes por daño moral directo a los actores de este juicio, así como a sus dos menores hijos; C) El pago de los gastos médicos generados por la recuperación médica de los actores y sus hijos; D) El pago de los gastos y costas; E) Que se condene a los demandados para que, a su costa, se publique un extracto de la sentencia definitiva que por daño moral se dicte en el presente juicio, en dos periódicos de circulación nacional. 
aspectos sustantivos de la responsabilidad civil extracontractual en México ${ }^{23}$, existen algunos datos que llaman la atención, como lo veremos de inmediato.

Las pretensiones indemnizatorias hechas valer por el actor en primera instancia fueron subclasificadas en seis rubros: (i) daños y perjuicios ${ }^{24}$; (ii) daño moral $^{25}$; (iii) publicación de un extracto de la sentencia; (iv) pago de intereses; (v) costas y gastos; (vi) alguna otra pretensión no incluida en las anteriores. En esta parte, por tanto, trabajaremos con la información desglosada, de tal manera de medir de modo individual si una determinada pretensión se acoge o se rechaza por los tribunales de instancia. Similar criterio utilizaremos tratándose de la apelación en cuanto a si confirma o modifica la sentencia recurrida. No así, sin embargo, en el plano federal en el que solo se analiza si el amparo fue acogido o si fue rechazado.

Casos en que se demanda indemnización por daños y perjuicios

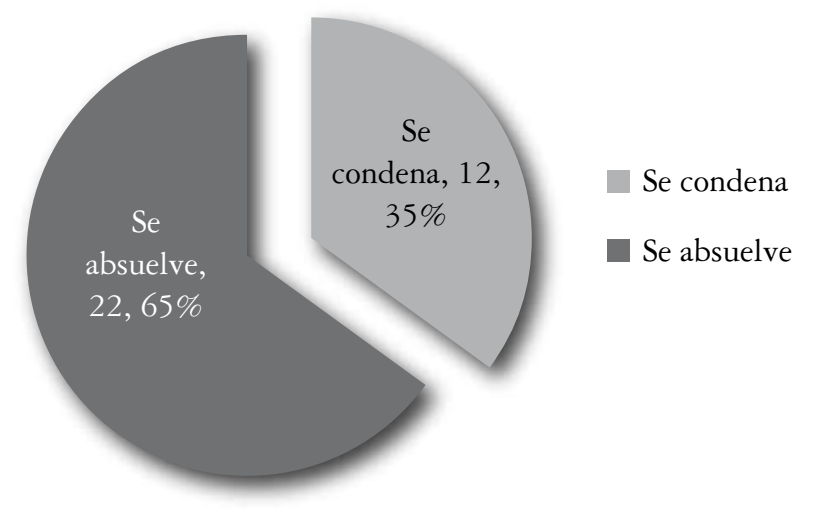

${ }^{23} \mathrm{Al}$ respecto, puede verse mi trabajo “QQué hacen los civilistas en México?”, El Foro, Barra Mexicana Colegio de Abogados, 16 a época, t. XXII, Nº 1, 1er. Semestre, 2009, págs. 91-123. Publicado también en: "O que fazem os civilistas no México?, Revista Trimestral de Direito Civil (RTDC), vol. 38 (abril-junio), 2009.

${ }^{24}$ De conformidad con el art. 2108 del CCDF el daño se define como "la pérdida o menoscabo sufrido en el patrimonio por la falta de cumplimiento de una obligación”. Equivale a lo que la doctrina denomina daño emergente. El perjuicio, por su parte, es definido en el art. 2109 como "la privación de cualquiera ganancia lícita, que debiera haberse obtenido con el cumplimiento de la obligación”. Equivale a lo que en doctrina se denomina lucro cesante.

${ }^{25}$ El CCDF en su art. 1916 define daño moral de la siguiente manera: "Por daño moral se entiende la afectación que una persona sufre en sus sentimientos, afectos, creencias, decoro, honor, reputación, vida privada, configuración y aspecto físicos, o bien en la consideración que de sí misma tienen los demás. Se presumirá que hubo daño moral cuando se vulnere o menoscabe ilegítimamente la libertad o la integridad física o psíquica de las personas”. En general la reparación del daño moral constituye la pretensión más importante en los procesos de responsabilidad civil en México. 
En 34 procesos se demandó la indemnización de daños y perjuicios. Solo se concedió en 12 de ellos (35\%). Se absolvió al demandado de esta prestación en los restantes 22 procesos judiciales $(65 \%)$. Esta estadística llama la atención. Lógicamente sin la lectura del respectivo expediente de primera instancia no podemos saber con certeza por qué razón los jueces inferiores fueron poco proclives a conceder daños y perjuicios. Podría deberse a una deficiencia en la prueba del abogado del actor. Pero también podría suceder que los jueces estén siendo muy estrictos en la interpretación de los requisitos que se exigen para conceder una indemnización: culpa (o riesgo), daño y causalidad. Luego veremos al analizar las tasas de revocación, especialmente en amparo, que la explicación parece residir en el último aspecto mencionado.

Casos en que se demanda daño moral

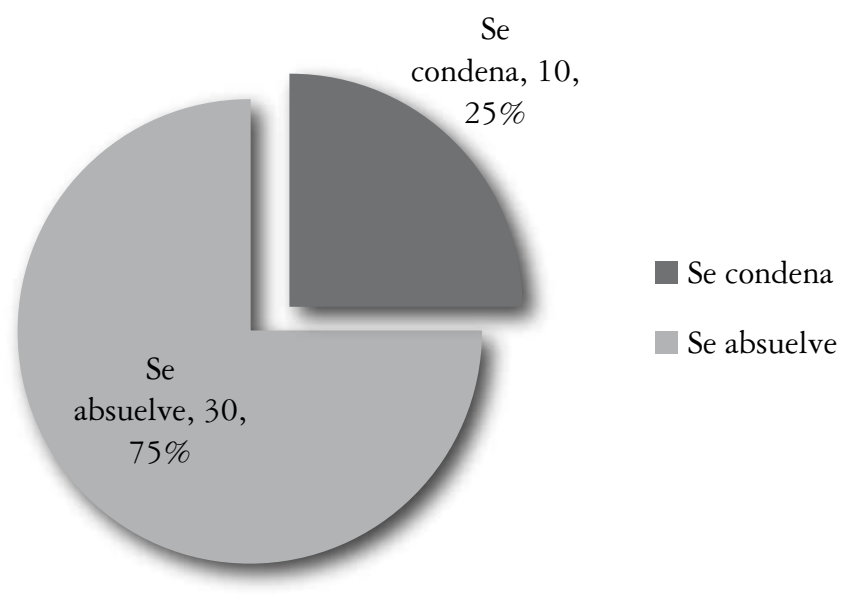

En 40 procesos se demandó el daño moral como indemnización. Solo se concedió en 10 de ellos, esto es, en $25 \%$. En los restantes 30 se desechó. Este dato llama la atención. La lectura de los amparos, en general, muestra que los jueces de instancia no han hecho una adecuada aplicación de la presunción contenida en el artículo 1916 del CCDF antes transcrito, ni de la prueba en la que el actor intentó acreditarlo. En general en esta materia debemos tener presente que los montos que los tribunales en México suelen otorgar por este rubro ha sido muy bajo ${ }^{26}$, con una reciente notable excepción que merece -no aquí, por cierto- por sí sola un extenso comentario. Me refiero al amparo directo en revisión 30/2013 resuelto por la Corte Suprema el 27 de febrero de 2014, que incorporó por primera vez en el derecho mexicano por vía de varias tesis la discutible figura de los daños punitivos.

${ }^{26}$ C.fr. Juan Carlos Marín G., "Daño moral en la regulación del derecho civil mexicano”, en Eréndira Salgado L. y Agustín Ramírez R. (coordinadores), Error y Daño Moral, Porrúa, 2013, pp. 27-58. 
Casos en que se demanda la publicación de un extracto de la sentencia

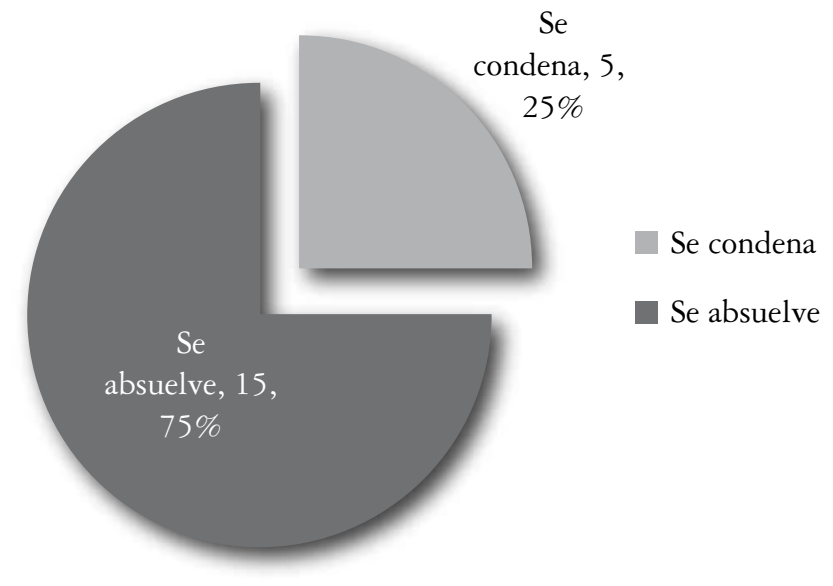

En 20 procesos se pidió que se publicara un extracto de la sentencia. Solo se concedió esta pretensión en 5 de ellos, es decir, en 25\%. Se rechazó en los 15 restantes. La mayoría dice relación con procesos en lo que hubo un atentado al honor del actor.

Casos en que se demandan gastos y costas

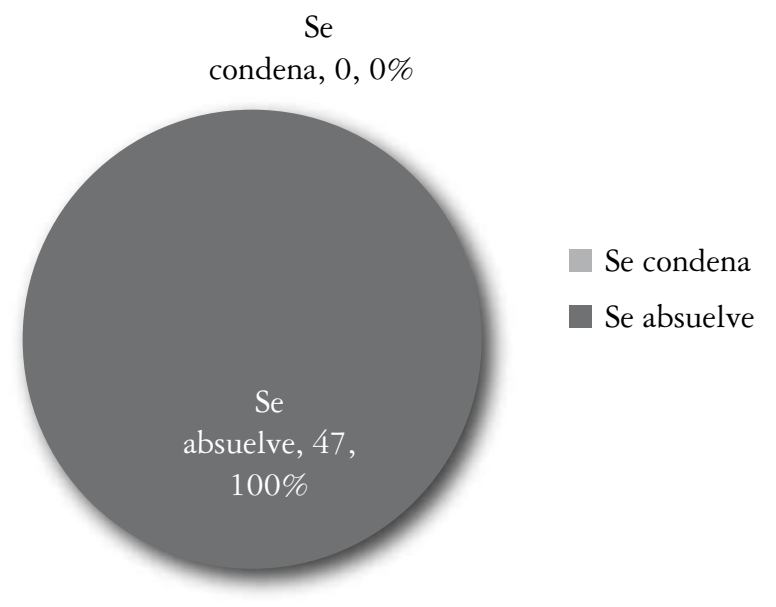

En 47 procesos se pidió el pago de los gastos y costas. Los jueces a quo sistemáticamente rechazaron esta pretensión. Esto se debe a la deficiente regulación legal. El legislador es partidario de que cada litigante asuma las costas y gastos del proceso (arts. $139 \mathrm{y}$ 140 del CPCDF). En general solo se condena en costas a la parte que ha procedido con temeridad o mala fe. Esto último no sucedió en ningún proceso en primera instancia, no al menos en opinión de los jueces a quo. 
Casos en que se demanda el pago de intereses

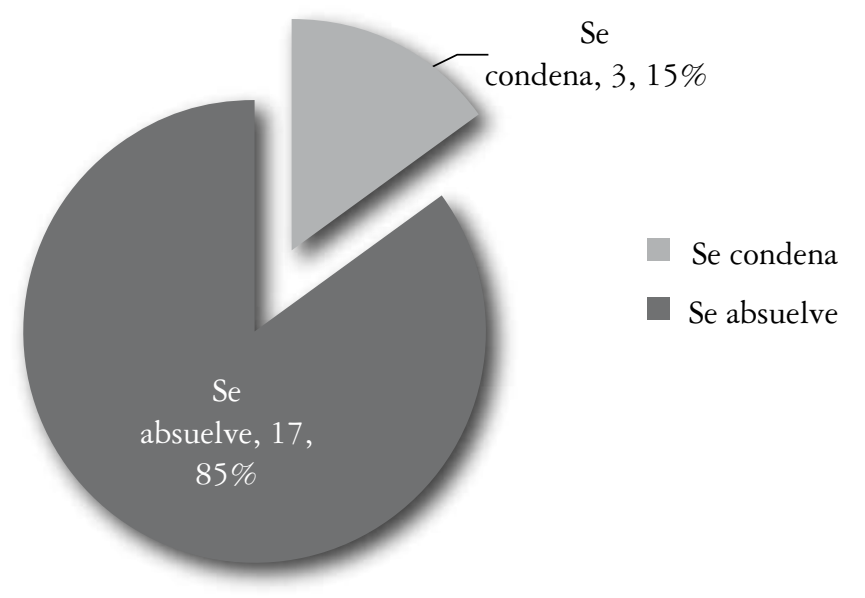

El pago de intereses se pidió en 20 procesos. Solo se concedió en tres. En los restantes 17 se rechazó. Los intereses debieran concederse siempre que se otorgue alguna pretensión indemnizatoria. El efecto declarativo de la sentencia así lo exige.

Casos en que se demandan otras pretensiones

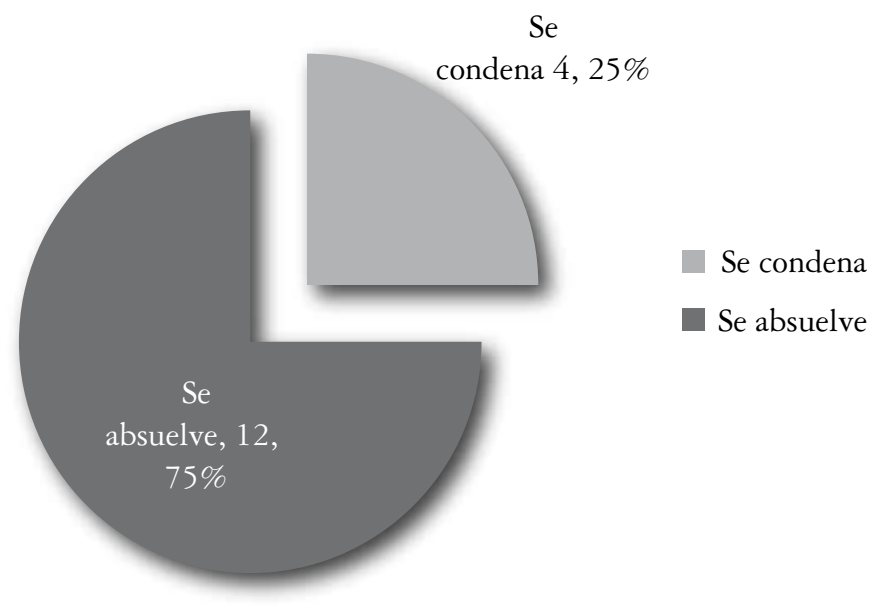

Finalmente en 16 procesos se demandó alguna prestensión diversa de las enumeradas con anterioridad (por ejemplo, el retiro de todos los productos de tiendas de vestir, la prohibición de comercialización de determinados productos, o la inhabilitación de ejercicio de alguna profesión). El resultado no fue muy diverso. Solo se concedieron en 4 procesos. En 12 se rechazaron. 
En resumen, los jueces de primera instancia no fueron especialmente generosos con las pretensiones indemnizatorias solicitadas por los actores en sus demandas. Fueron particularmente estrictos con las solicitudes que buscaban la reparción del daño moral. Veamos qué sucedió en segunda instancia.

\section{SEgunda InStancia: ReCURSo de APElación}

A continuación analizaremos lo que sucedió ante el tribunal ad quem. No se olvide que en el sistema procesal civil de Ciudad de México la sentencia de primera instancia que acoge una o más de las pretensiones del actor no puede ejecutarse. La apelación en contra de esta sentencia se concede, en términos procesales, en ambos efectos (artículo 700 , fracción I, CPCDF). El juez de primera instancia no puede, por tanto, seguir conociendo del asunto porque su competencia está suspendida (artículos 694 párrafo final y 702 del CPCDF). En nuestro sistema procesal apela el que sufre un agravio, es decir, el que no obtuvo todo lo que pidió (artículo 689 del CPCDF). Esto posibilita que tanto el actor como el demandado puedan apelar de la misma sentencia. Así, por ejemplo, si el demandado solicitó el rechazo total de la demanda y fue condenado a pagar tan solo una de las pretensiones del actor, puede apelar. En el mismo evento el demandante podrá recurrir por el resto de las pretensiones no concedidas.

Ya sabemos que el tribunal ad quem tiene plena competencia para resolver el fondo de la disputa. En términos del artículo 688 del CPCDF puede confirmar, revocar o modificar la resolución del inferior. Para efectos de este trabajo la modificación la tomamos como revocación porque analizamos pretensiones específicas.

Indemnización por daños y perjuicios. Comparativo entre las sentencias de primera y segunda instancia

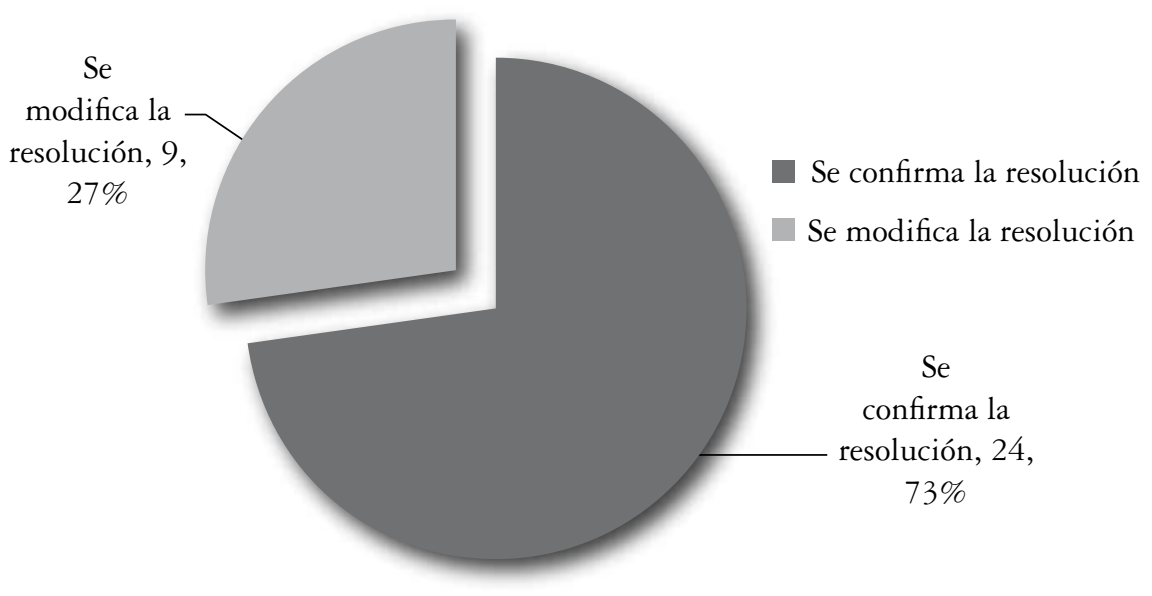


Como se aprecia en su gran mayoría las salas del TSJDF confirmaron las resoluciones de los jueces civiles. Esto quiere decir que la sentencia de primera instancia (fuere que hubiere rechazado la demanda, fuere que la hubiere acogido) tiende a ser confirmada por el superior. Como la mayoría de las sentencias de los jueces inferiores rechazaron las pretensiones indemnizatorias de los actores, según lo acabamos de ver, la situación descrita en este gráfico afecta más a estos últimos. Los afecta más porque en la mayoría de los procesos son los actores quienes recurren de apelación buscando la revocación de lo resuelto en primera instancia. Uno supone que si la tasa de confirmación es alta en el tribunal ad quem los incentivos para apelar deberían ser bajos. Luego veremos que esto no es así.

Daño moral. Comparativo entre las sentencias de primera y segunda instancia

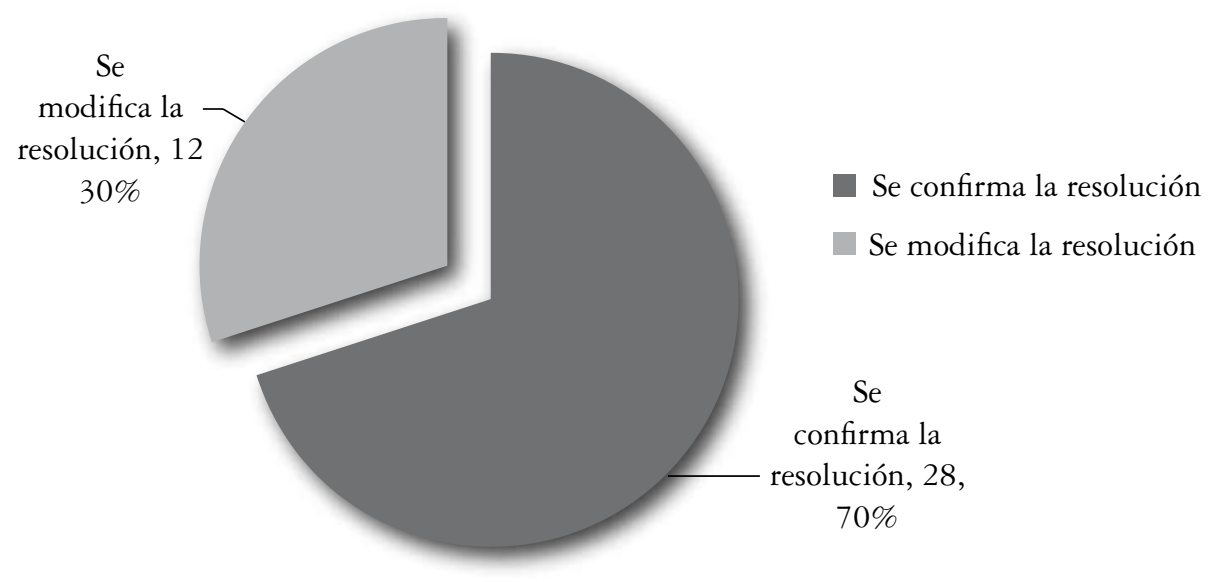

Algo similar sucede con el daño moral. La enorme mayoría de las decisiones de los tribunales inferiores se ven confirmadas en apelación. La situación para los actores -en lo que constituyen normalmente la principal pretensión indemnizatoria en el sistema jurídico mexicano- no son muy auspiciadoras en la esfera local.

Tratándose de la publicación de un extracto de la sentencia algo disminuye la tasa de confirmación por parte del tribunal ad quem, pero ella continúa siendo muy alta. De todos modos esta pretensión, según lo mostraremos al analizar las materias acerca de las que se litiga en Ciudad de México, se encuentra muy vinculada a las demandas que buscan reestablecer el honor de las personas. Es una pretensión muy focalizada en un concreto tipo de juicio y que desde el 2006 tiene una especial normativa en esta Ciudad ${ }^{27}$.

${ }^{27}$ Me refiero a la ley de responsabilidad civil para la protección del derecho a la vida privada, el honor y la propia imagen en el Distrito Federal. El art. 39 de esta ley establece: "La reparación del daño comprende la publicación o divulgación de la sentencia condenatoria, a costa del demandado, en el medio y formato donde fueron difundidos los hechos y/u opiniones que constituyeron la afectación al patrimonio moral". 
Publicación de un extracto de la sentencia. Comparativo entre las sentencias de primera y segunda instancia

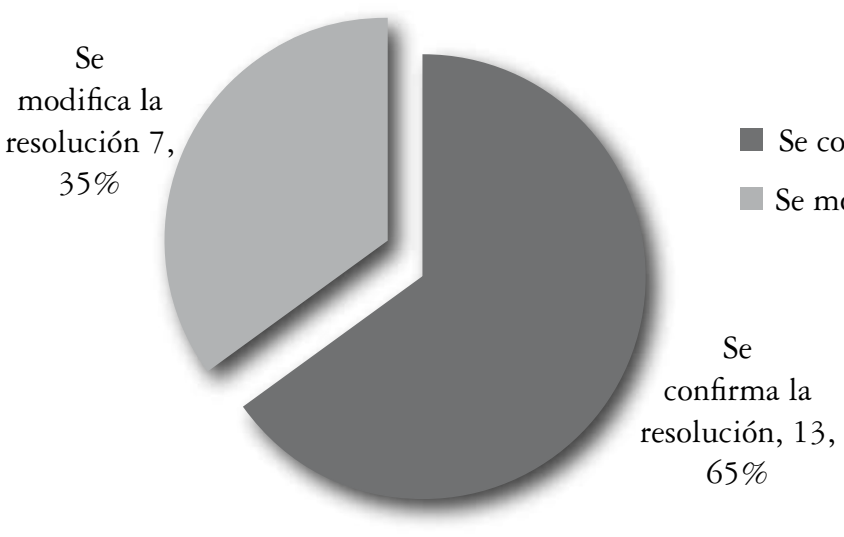

Casos en que se demandan gastos y costas

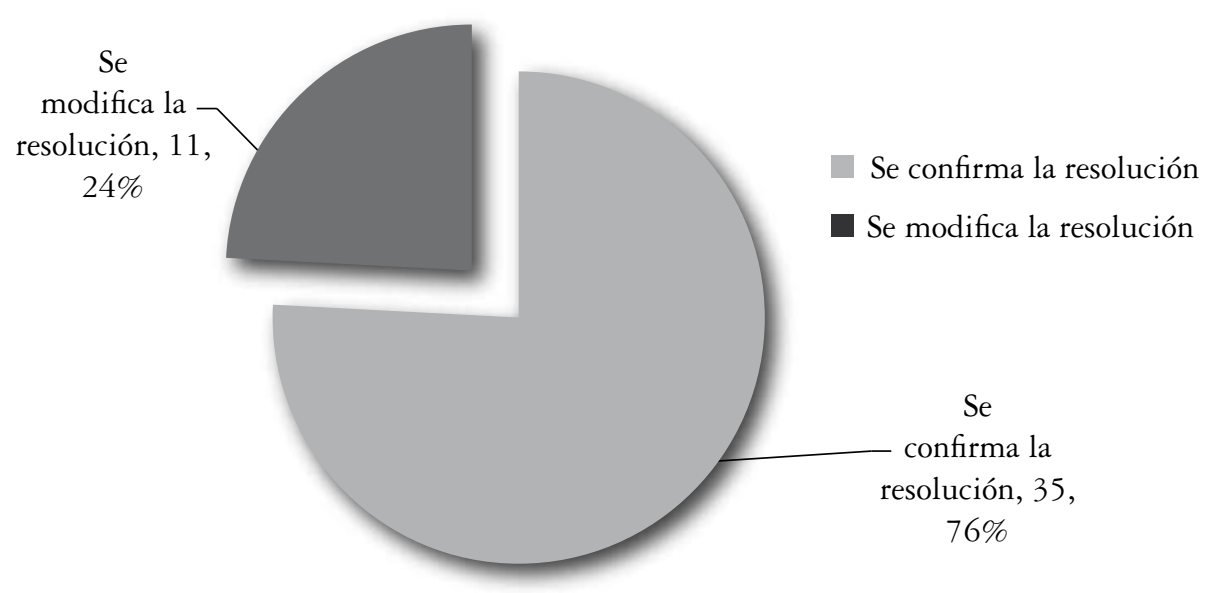

En el rubro de gastos y costas la situación es simple de analizar. Se recordará que los jueces inferiores rechazaron el $100 \%$ de esta solicitud, independiente de quién la hubiere efectuado (el actor, el demandado o ambos). Las salas del TSJDF si bien confirmaron ampliamente las decisiones del inferior, la revocaron en $24 \%$, es decir, en uno de cada cuatro procesos condenaron a alguna de las partes a pagar los gastos y costas originados en la causa. Algún grado de temeridad o mala fe en los litigantes encontraron los magistrados que los jueces no vieron. 
Pago de intereses. Comparativo entre las sentencias de primera y segunda instancia

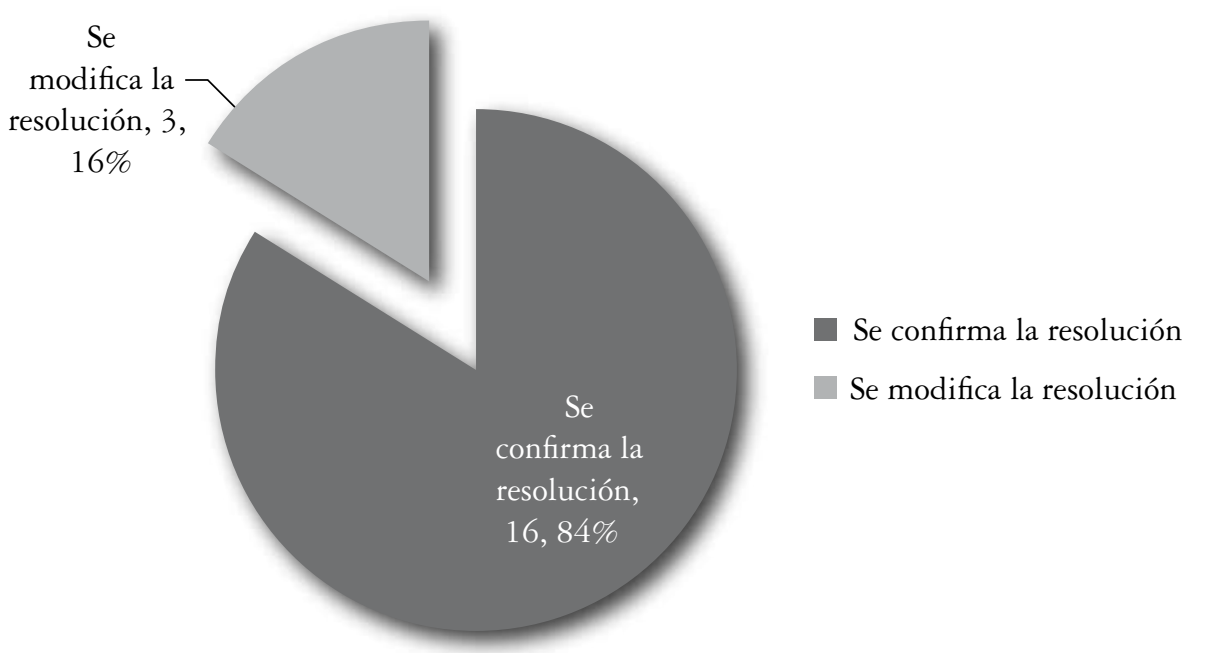

La tendencia hasta aquí vista se incrementa en el rubro de pago de intereses. Hay una altísima tasa de confirmación. Si la sentencia rechazó las pretensiones indemnizatorias debe rechazar también el pago de intereses. La situación inversa debería producirse en los procesos en los que se condena al demandado.

Otras pretensiones. Comparativo entre las sentencias de primera y segunda instancia

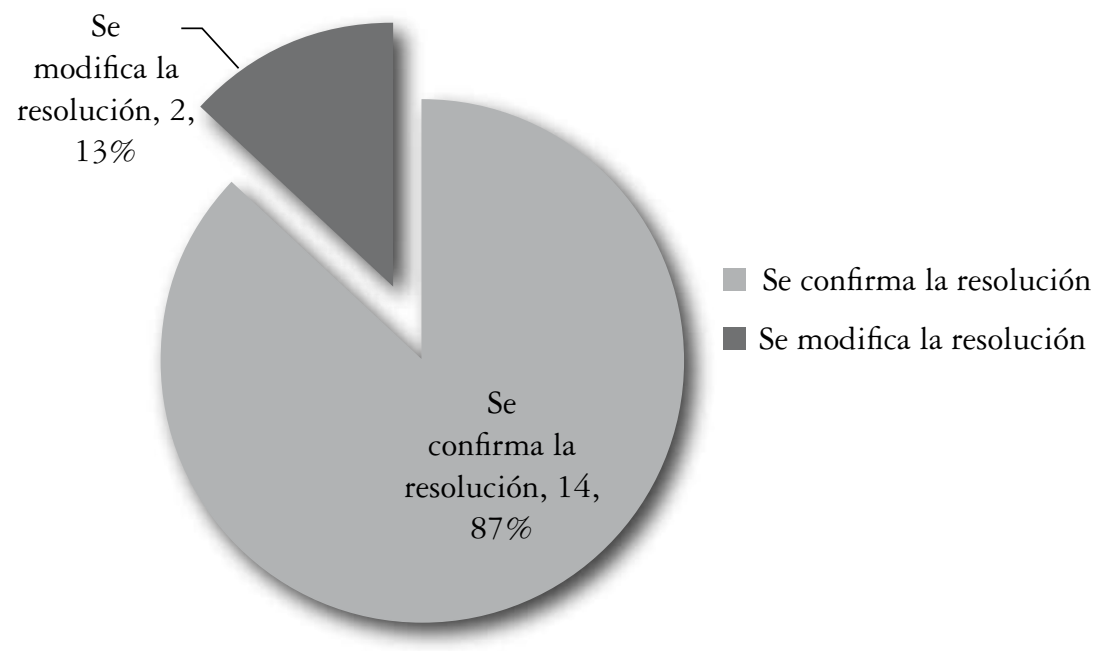


Lo mismo ocurre con las demás pretensiones que hizo valer el actor en su demanda. La enorme mayoría de decisiones del juez a quo son confirmadas por el ad quem.

Confirmación/modificación de la sentencia de primera instancia (Exceptuando el pago de gastos y costas)

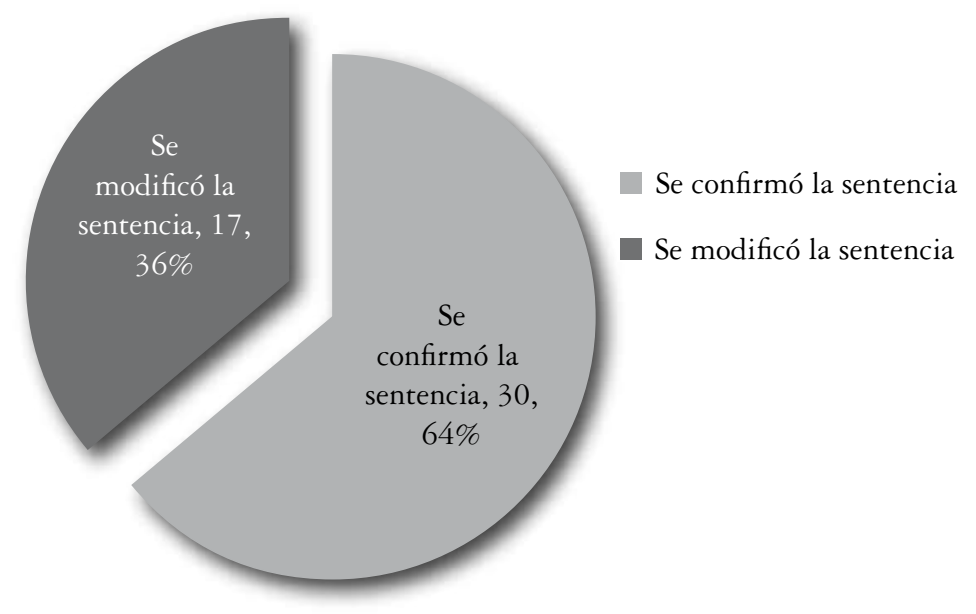

Finalmente, si tomamos todos los rubros - con excepción de los gastos y costas- la relación entre la primera y la segunda instancia en Ciudad de México es la siguiente: $64 \%$ de las sentencias son confirmadas en apelación. Solo $36 \%$ son modificadas. Si la tasa de confirmación es alta los incentivos a apelar deberían ser bajos. Ya hemos dicho que esto no es así. Creo que esta situación se explica porque los abogados saben que después de la justicia local viene el recurso de amparo, pero para llegar a él deben, en primer lugar, agotar las medios de impugnación locales. ¿Es la justicia local, para los abogados en Ciudad de México, solo una excusa para llegar a la federal?

\section{JUICIO DE AMPARO DIRECTO}

La situación hasta aquí descrita va a cambiar al analizar lo que sucede fuera de la esfera local y nos adentremos en el ámbito federal. De inmediato veremos que la mayoría de los amparos han sido procedentes. Particularmente ilustrativa es la situación que se presenta cuando el recurrente es el actor. La mayoría de estos amparos son acogidos.

Dos precisiones importantes debemos hacer antes de entrar en el análisis de lo resuelto por los TCC: (i) a diferencia del desglose de pretensiones que hicimos en las instancias locales, tratándose del amparo solo analizamos si la justicia de la unión ampara o no al quejoso, es decir, si acoge o rechaza el recurso. Como se sabe, es suficiente con que los TCC acepten un agravio para que el amparo sea acogido; (ii) Hemos dicho que, en general, si el amparo directo es rechazado el proceso judicial termina. Lo anterior no 
es técnicamente correcto. Eventualmente, quien ha perdido puede recurrir de amparo en revisión ante la Suprema Corte de Justicia. Solo que en este caso la discusión ya no es de legalidad, sino exclusivamente de constitucionalidad: si existe en el fallo del TCC algún cuestionamiento de constitucionalidad o de interpretación directa de algún precepto constitucional. Es un recurso en el que la Suprema Corte tiene gran discrecionalidad y que acoge en contadas ocasiones. Nuestro trabajo no analiza esta eventualidad.

Resolución del juicio de amparo

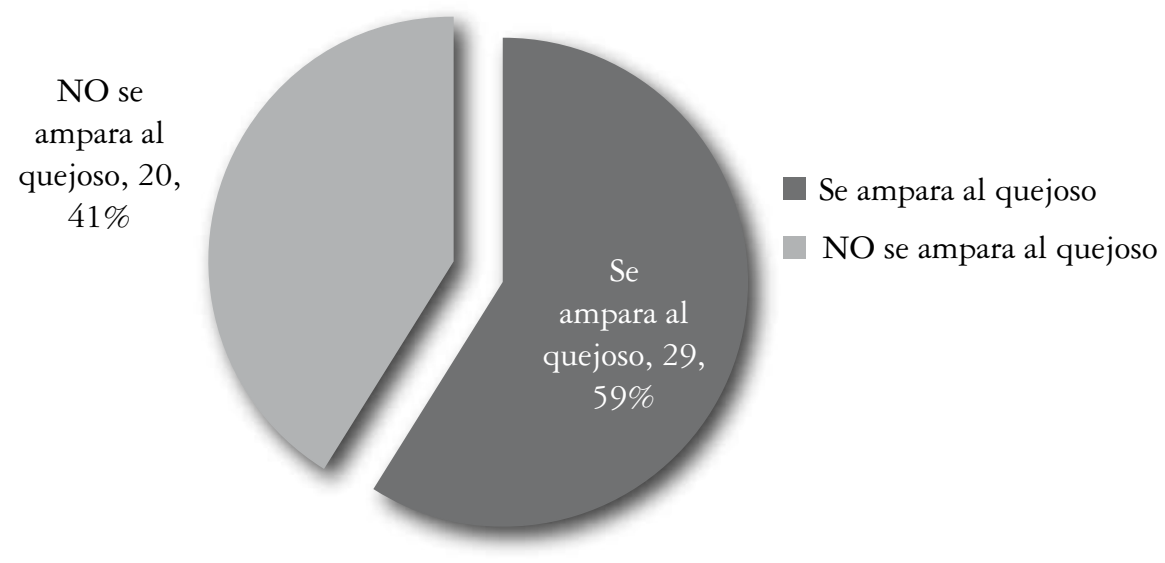

En términos generales, casi $60 \%$ de los amparos presentados fueron acogidos por los TCC. La cifra es alta, lo que produce un notable incentivo a recurrir de amparo. Como hemos dicho esta situación va a cambiar buena parte de la historia que hasta aquí hemos visto en cuanto a la duración de los procesos declarativos. Que se acepte el recurso por el TCC significa que deberá emitirse por el tribunal ad quem (local) una nueva sentencia de segunda instancia. Como se recordará, el TCC no tiene competencia para resolver el fondo de la disputa y debe, por tanto, reenviar el asunto para que el mismo tribunal de segunda instancia que ya se pronunció acerca del tema vuelva a hacerlo. ¿En qué sentido? En el indicado por el TCC en su resolución del amparo. Aquí las posibilidades son variadas, algunas más simples que otras. Por ejemplo, si el TCC hubiere acogido el amparo porque en su opinión se debió conceder la pretensión de indemnización del daño moral, la nueva sentencia que dicte el tribunal ad quem deberá otorgar dicha pretensión. Más difícil es establecer el monto del referido daño. El TCC no puede determinar en su sentencia una cantidad que deba ser seguida por el tribunal de instancia. Este es un aspecto que queda entregado más bien a la discrecionalidad del tribunal ad quem, de acuerdo con la prueba que se hubiere rendido y a la valoración que de ella hiciere. Hemos dicho que las posibilidades son diversas. Podría también suceder que el TCC haya acogido el recurso de amparo porque el tribunal ad quem hubiere concedido daños y perjuicios que no debieron otorgarse. Este evento es más simple, pues la nueva sentencia de segunda instancia denegará, ahora, dichos rubros. 


\section{¿Quién promueve el amparo?}

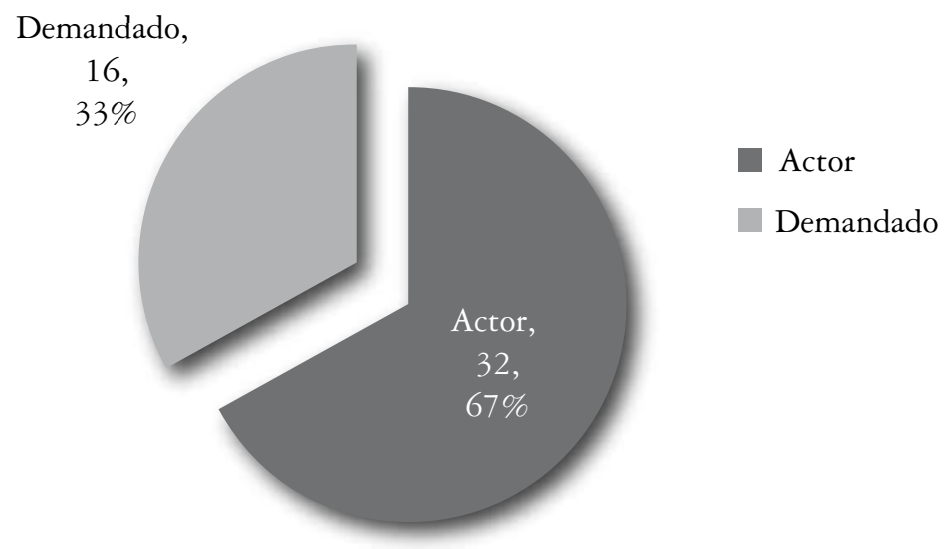

Esta gráfica -en conjunto con la siguiente- nos muestra que la posición del actor después del amparo debería mejorar en los tribunales locales. En casi el $70 \%$ de los amparos presentados el recurrente (quejoso) fue el actor. Solo en $33 \%$ lo fue el demandado. Lo anterior es del todo coincidente con el hecho de que los tribunales de instancia, por regla general, denegaron las pretensiones indemnizatorias de los actores.

La justicia de la Unión ampara y protege al...

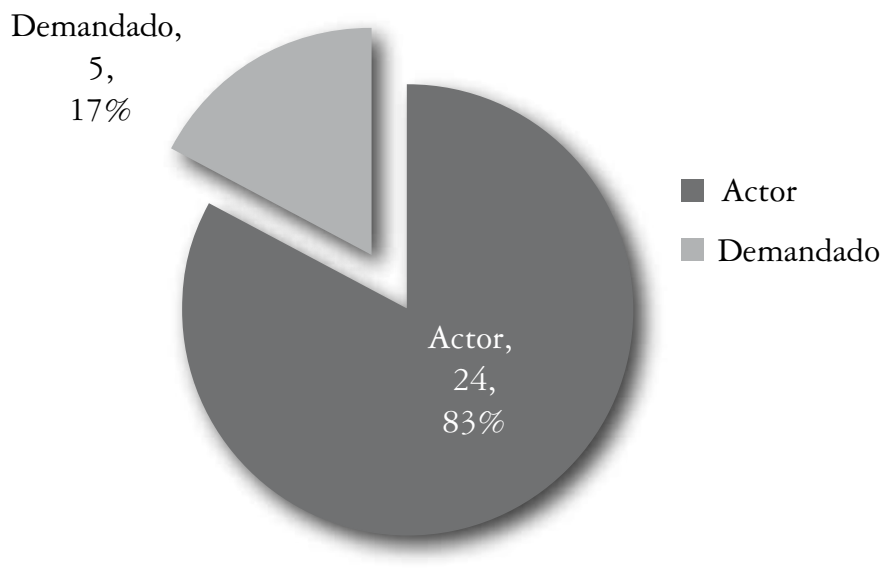

De los casos en los que el actor presentó el amparo (casi el $70 \%$ según la gráfica anterior) más del $80 \%$ fueron acogidos por los TCC. Esta es una tasa particularmente alta que evidencia al menos dos cosas: (i) refuerza la idea de que los jueces locales han sido muy estrictos con los actores en este tipo de procesos; y (ii) que la duración promedio de estos procesos es más larga de lo que el análisis de la justicia ordinaria refleja. Uno 
entiende que la gran mayoría de estos amparos se han traducido en nuevas sentencias de segunda instancia que han debido acoger - una o más- las pretensiones originalmente denegadas a los actores.

Cuando la segunda instancia condena al demandado, promueve amparo el...

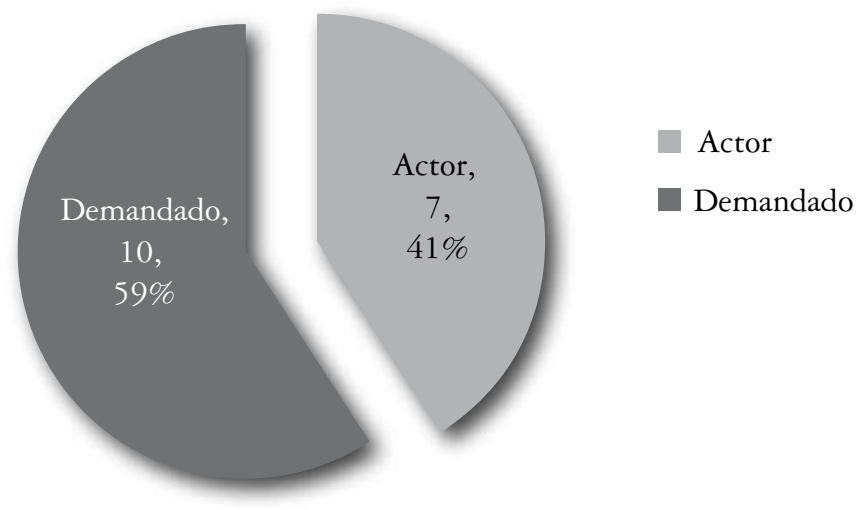

Puede llamar la atención que en los casos en los que se condena al demandado el actor recurra de amparo en $41 \%$ de los casos. Ello se explica porque en su gran mayoría las sentencias no son binarias: se concede todo o se niega todo. Normalmente, en los procesos en los que el demandado es condenado a pagar una suma de dinero, lo es por alguna de las pretensiones indemnizatorias del actor, no por todas, ni por todo el monto pedido. La sentencia de segunda instancia condenatoria puede, por tanto, también causar un agravio al actor. Esto es lo que explica que este se haya amparado en el $41 \%$ de estos casos.

Cuando la segunda instancia absuelve al demandado, promueve amparo, el...

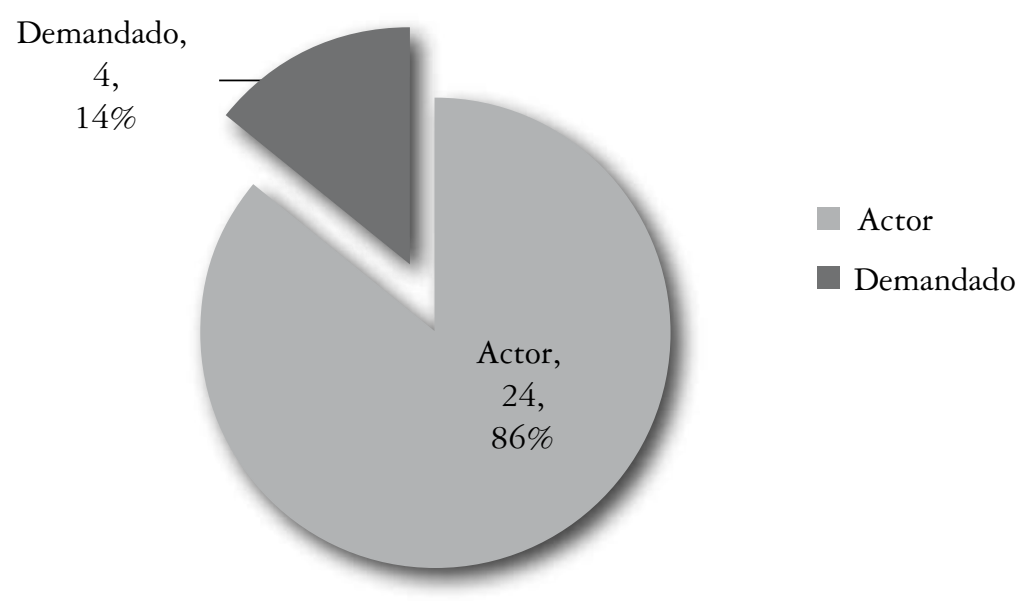


La cifra que muestra este gráfico es muy razonable. Si la sentencia absuelve al demandado naturalmente quien sufre agravio con esta resolución es el actor. De allí que en casi el $90 \%$ de los casos sea él quien interpone el recurso de amparo. El demandado, en estos casos, suele recurrir buscando obtener alguna condena en costas de la contraparte.

\section{MATERIAS}

El último aspecto que abordaremos en este trabajo busca responder la siguiente interrogante: ¿sobre qué se litiga en el DF en materia de responsabilidad civil extracontractual?

Veamos el siguiente gráfico:

\section{Daños a la integridad física}

Por

el delito de

lesiones, 2,

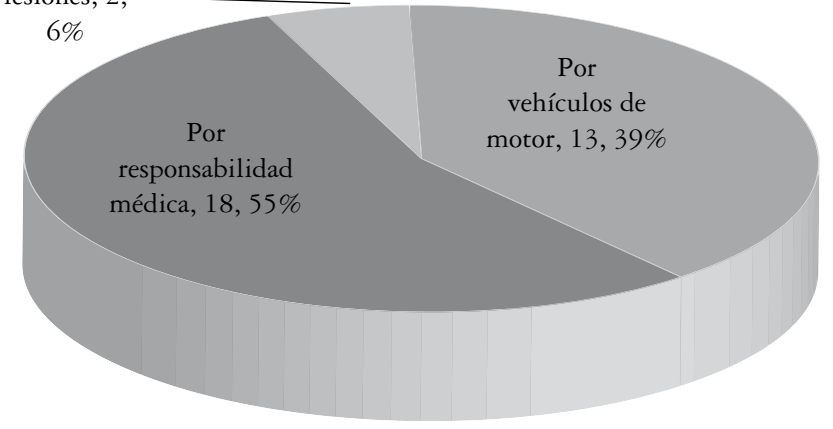

Por vehículos de motor

Por responsabilidad médica

Por el delito de lesiones

Tratándose de daños a la integridad física, esto es, los que modernamente se denominan daños personales ${ }^{28}$, tres son los grandes rubros que los originan: daños provocados por responsabilidad médica (55\%); daños causados por vehículos de motor, ya fuere atropellos o colisiones de vehículos (casi el 40\%); lesiones y muerte provocadas fuera

${ }^{28}$ La figura de los daños personales o corporales se viene abriendo camino en los últimos lustros y tiende a transformarse en una categoría autónoma, atendidos los particulares efectos que produce en el terreno patrimonial y extrapatrimonial. Respecto de este punto la doctrina ha dicho: "Del daño corporal se siguen consecuencias patrimoniales de dos tipos diferentes. Ante todo, los gastos necesarios para el tratamiento médico y el cuidado de la víctima y las demás expensas que típicamente constituyen daño emergente. Además, se siguen efectos, a menudo delicados desde el punto de vista de su apreciación, que se expresan en el lucro cesante por las sumas que la víctima deja de ganar por la supresión o la disminución de su capacidad para generar ingresos. Los perjuicios no patrimoniales resultantes del daño corporal también presentan peculiaridades. La víctima está expuesta, por un lado, a dolor físico y a aflicciones puramente mentales y, por otro a la privación de agrados de la vida. La indemnización respecto del primer conjunto de perjuicios compensa el dolor o aflicción (pretium doloris); en el segundo, compensa las oportunidades de una buena vida (que genéricamente pueden ser denominadas perjuicio de agrado)". Barros, Enrique, Tratado de responsabilidad extracontractual, Editorial Jurídica de Chile, 2006, pág. 234. 
del tráfico de automóviles (6\%), por ejemplo, muerte en una piscina de propiedad del demandado, quemaduras por explosión de un camión que trasporta gas, caída en un supermercado, etcétera.

\section{Daño moral}

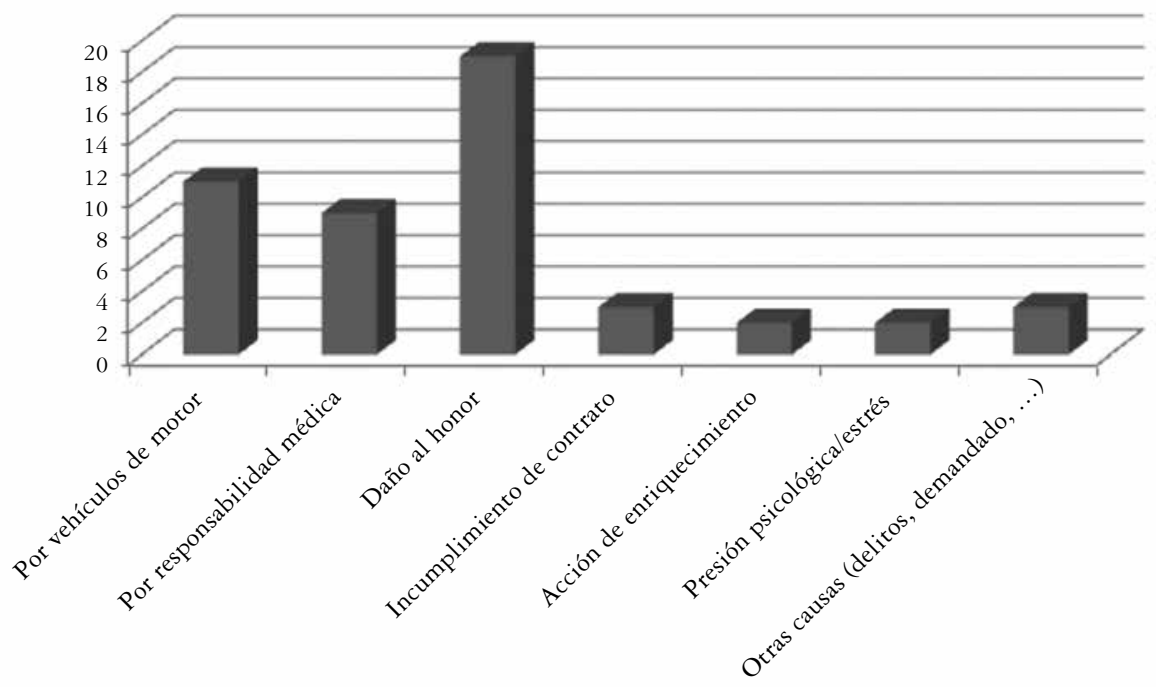

Tratándose de daño moral la fuente de los mismos se concentra en tres grandes rubros: en primer término los denominados daños al honor por imputaciones injuriosas o calumniosas; en segundo lugar los daños provocados por vehículos a motor y, finalmente, los daños provocados en el ámbito de la responsabilidad médica. Se han adicionado otros daños que no deberían estar en esta gráica porque su fuente no es la responsabilidad extracontractual sino la contractual, o bien porque se trata de casos de enriquecimiento ilegítimo. Sin embargo, son tratados aquí porque las peticiones de los actores suelen confundir estas tres fuentes y tratarlas como reglas de responsabilidad extracontractual por daño moral.

En resumen, cuatro son las principales materias de las que se litiga en Ciudad de México tratándose de los procesos judiciales por responsabilidad civil extracontractual: (i) daños provocados por vehículos a motor; (ii) daños que derivan de la responsabilidad médica; (iii) daños al honor y la reputación de las personas; y (iv) lesiones de una fuente diversa de las (i) y (ii) precedentes. A ellos debemos agregar un quinto subconjunto que comprende disímiles temas, entre otros, abuso de derecho (artículo 1912 del CCDF); responsabilidad civil de jueces y magistrados (artículos 728-737 del CPCDF); uso indebido de marcas bajo el amparo de la legislación de propiedad industrial; responsabilidad patrimonial del DF, por ejemplo, por una clausura ilegal, por fallas del Registro Público de la Propiedad o por privación de un avión de propiedad del actor 
por un proceso penal en el que se absolvió a los acusados (artículo 1927 del CCDF). Todas estas materias concentran prácticamente todos los amparos con los que hemos trabajado en esta investigación.

\section{Conclusiones}

Un proceso declarativo en materia de responsabilidad civil extracontractual en Ciudad de México tiene, en el período analizado (1995-2008), una duración promedio de 29,23 meses, es decir, poco menos de dos años y medio. Este tiempo es muy razonable, teniendo presente lo que tardan en resolverse este tipo de procesos judiciales en otras latitudes. El dato es positivo. Es bueno que las sentencias se pronuncien en un lapso no muy lejano en relación con la presentación de la demanda. El sentido de la justicia se valora más en estos casos. Lo contrario sucede cuando los procesos tardan cinco, diez o más años en decidirse.

La anterior, con todo, se ve opacado si tenemos presente que los jueces locales de Ciudad de México fueron particularmente estrictos con los actores al momento de indemnizar los daños y perjuicios por ellos reclamados. Las sentencias de instancia, especialmente, las de primera, generalmente rechazaron las pretensiones formuladas por los demandantes. Si tenemos presente que estos fallos fueron confirmados en $65 \%$ por los jueces de apelación, se comprenderá que la situación de los actores no fue muy halagüeña en la esfera local. La situación cambia de manera importante con el juicio de amparo directo. Los jueces federales en casi $60 \%$ dejaron sin efecto las sentencias de segunda instancia. Cuando el que presentó el amparo fue el actor el nivel de anulación alcanzó ¡más del 80\%! Los magistrados de los TCC fueron, por tanto, mucho más proclives a otorgar las pretensiones provenientes de la responsabilidad civil extracontractual, especialmente las referidas al daño moral. Lo anterior significa que en definitiva los procesos judiciales duraron más tiempo que el señalado en el párrafo anterior.

En lo que dice relación con las materias que se litigan en Ciudad de México son cuatro los grandes rubros: daños provocados por responsabilidad médica; daños causados por vehículos de motor, ya fuere atropellos o colisiones de vehículos; lesiones y muerte provocadas fuera del tráfico de automóviles; y daños al honor por imputaciones injuirosas o calumniosas.

El sistema de tesis debería repensarse. Si bien es poco factible proponer su eliminación -porque entiendo que es parte importante de la cultura jurídica del país-algunas mejoras podrían introducirse, como, por ejemplo, hacer alguna referencia a los hechos de la causa y, fundamentalmente, crear un sistema que permita de manera simple acceder directamente a los amparos tan pronto han sido firmados por los magistrados, con absoluta independencia de si confeccionaron o no alguna tesis. Esto ayudaría mucho a conocer mejor los criterios de los tribunales superiores de México. También es deseable que se genere algún mecanismo estadístico que permita dar seguimiento a los fallos de apelación (llamados tocas) con los juicios de amparos, y de esa forma poder apreciar toda la película y no solo una parte de ella. 
Finalmente, se debería pensar si en el siglo XXI es todavía razonable mantener el doble juego entre esfera local y federal que ha caracterizado a la justicia civil en México por tantos años. Como se sabe, en el sistema de EE.UU. esta situación no ocurre. Los procesos que inician en la esfera local terminan en ella y los que inician en el ámbito federal termina en él. Podría revisarse la forma en la que ha operado el denominado juicio de amparo directo y entregar competencia a los TCC para que puedan resolver de una vez el fondo de la disputa. Esto agilizaría la resolución de los conflictos en el país y evitaría más de un problema práctico que ahora se produce.

\section{BiBLIOGRAFÍA}

Barros, Enrique, Tratado de responsabilidad extracontractual, Editorial Jurídica de Chile, 2006. Boré, Jacques, Boré, Louis, La Cassation en matière civile, Paris, Dalloz, 2008.

Chase-Hersjkoff (eds.), Civil litigation in comparative context, Thomson-West, EE.UU., 2007. Chemerinsky, Erwin, Federal jurisdiction, New York, Wolters Kluwer, 5a. ed., 2007.

Douence, Maylis, Azavant, Marc, Institutions Jurisdictionnelles, Paris, Dalloz, 2a . ed., 2014.

Ervo, L. and Nylund, A. (ed.), The future of civil litigation. Access to courts and courts-annexed mediation in Nordic countries, Springer, 2014.

Fix-Zamudio, Héctor, "Reflexiones sobre la naturaleza procesal del amparo", en Ensayos sobre el derecho de amparo, México, Porrúa, $2^{a}$. ed., 1999, pp. 97-154.

Fix-Zamudio, Héctor, "Presente y futuro de la casación civil a través del juicio de amparo mexicano", en Ensayos sobre el derecho de amparo, México, Porrúa, 2a. ed., 1999, pp. 237-284.

Fix-Zamudio, Héctor y Cossío, José Ramón, El poder judicial en el ordenamiento mexicano, México, Fondo de Cultura Económica, 1996 (reimpresión 1999).

Glannon, Joseph W., Civil Procedure, New York, Wolters Kluwer, 2013.

Kramer, X.E. and CH Van Rhee, Ch. (eds.), Civil litigation in a globalizing world, Springer, 2012.

Marín G., Juan Carlos: “QQué hacen los civilistas en México?”, El Foro, Barra Mexicana Colegio de Abogados, 16ª época, t. XXII, Nº 1, 1er. Semestre, 2009, págs. 91-123. Publicado también en: "O que fazem os civilistas no México?, Revista Trimestral de Direito Civil (RTDC), vol. 38 (abril-junio), 2009.

Marín G., Juan Carlos, "Daño moral en la regulación del derecho civil mexicano", en Eréndira Salgado L. y Agustín Ramírez R. (coordinadores), Error y Daño Moral, Porrúa, 2013, pp. 27-58.

MaXeiner, J., Failures of American civil justice in international perspective, Cambridge, 2011.

Trocker, N. and Varano, V. (ed.), The reforms of civil procedure in comparative perspective, Torino, 2005. UZELAC, A. (ed.), Goals of civil justice and civil procedure in cotemporary juidicial system, Springer, 2014. VAN RheE, Ch. and F. Yulin, F, (eds), Civil litigation in China and Europe, Springer, 2014.

Van Rhee, Ch., (ed.), The Law's delay. Essays on undue delay in civil litigation, Intersentia, 2004. Zuckerman, A. S. S., Civil justice in crisis, Oxford University Press, 2000. 
